\title{
Observational Case Study of a Persistent Cold Pool and Gap Flow in the Columbia River Basin
}

\author{
Bianca Adler, ${ }^{\mathrm{a}, \mathrm{b}}$ JAmes M. WilczaK, ${ }^{\mathrm{b}}$ LAURA BiAnco, ${ }^{\mathrm{a}, \mathrm{b}}$ Irina DJALAlova, ${ }^{\mathrm{a}, \mathrm{b}}$ \\ JAMES B. DUNCAN JR., ${ }^{a, b}$ AND DAVID D. TURNER ${ }^{c}$ \\ ${ }^{\text {a }}$ Cooperative Institute for Research in Environmental Sciences, University of Colorado Boulder, Boulder, Colorado \\ ${ }^{\mathrm{b}}$ Physical Sciences Laboratory, NOAA, Boulder, Colorado \\ ${ }^{\mathrm{c}}$ Global Systems Laboratory, NOAA, Boulder, Colorado
}

(Manuscript received 25 January 2021, in final form 26 May 2021)

\begin{abstract}
Persistent cold pools form as layers of cold stagnant air within topographical depressions mainly during wintertime, when the near-surface air cools and/or the air aloft warms and daytime surface heating is insufficient to mix out the stable layer. An area often affected by persistent cold pools is the Columbia River basin in the Pacific Northwest, when a high pressure system east of the Cascade Range promotes radiative cooling and easterly flow. The only major outflow for the easterly flow is through the narrow Columbia River Gorge that cuts through the north-south-oriented Cascade Range and often experiences very strong gap flows. Observations collected during the Second Wind Forecast Improvement Project (WFIP2) are used to study a persistent cold pool in the Columbia River basin between 10 and 19 January 2017 that was associated with a strong gap flow. We used data from various remote sensing and in situ instruments and an optimal estimation physical retrieval to obtain thermodynamic profiles to address the temporal and spatial characteristics of the cold pool and gap flow and to investigate the physical processes involved during formation, maintenance, and decay. While largescale temperature advection occurred during all phases, we found that the cold-pool vertical structure was modulated by the existence of low-level clouds and that turbulent shear-induced mixing and downslope wind storms likely played a role during its decay.
\end{abstract}

SIGNIFICANCE STATEMENT: To integrate wind energy produced during cold-pool events into the electrical grid, accurate forecasts of these events and the associated rapid changes in wind speed are necessary. This still imposes a challenge for weather prediction models. In this study we aim to get a detailed understanding of the evolution and involved physical processes of a strong cold-pool event in the Columbia River basin, which is home to a large amount of wind energy production. The results will form the basis of a future model study to investigate the model's capability in capturing the cold pool and to identify potential flaws.

KEYWORDS: Complex terrain; Boundary layer; Clouds; Cold pools; Mesoscale processes; Microwave observations; Remote sensing; Surface observations; Wind profilers

\section{Introduction}

Persistent cold pools commonly occur during wintertime in orographic basins and valleys. They form as layers of cold stagnant air within topographically defined depressions when the air near the surface cools and/or the air aloft warms, which leads to an increase of temperature with height, that is, a temperature inversion (e.g., Whiteman et al. 2001). In contrast to diurnal cold pools, which form during the evening or nighttime and decay during the next day after sunrise, persistent cold pools may last for many consecutive days when the diurnal cycle of convective heating is insufficient to mix out the stable layer on a daily basis. The stable stratification in the cold pool suppresses the exchange of air within the depression and aloft that may have implications for air quality, and fog, low clouds, and precipitation may occur and impact air and ground transportation (e.g., Lareau et al. 2013). Weak winds within the cold pool and their rapid acceleration during its decay can impose a difficult challenge for weather prediction models, thereby making it more difficult to integrate the wind energy

Corresponding author: Bianca Adler, bianca.adler@noaa.gov produced during these events into the electrical grid (Francis 2008; Bossavy et al. 2013; Bianco et al. 2016).

Persistent cold pools have been studied in basins and valleys of different dimensions and shapes in field campaigns around the world. Some of the more recent examples are the Colorado Plateau Basin (Whiteman et al. 1999), the Columbia River basin (CRB) (Whiteman et al. 2001), and the Salt Lake Basin (Lareau et al. 2013) in the United States; the Rhine Valley (Flamant et al. 2006) and the Inn Valley (Haid et al. 2020) in Austria; the Avre River Valley in France (Chemel et al. 2016); and the Cerdanya Valley in the Pyrenees in Spain (Pagès et al. 2017). A common finding is that formation, maintenance, and decay of persistent cold pools are affected by processes occurring on multiple scales ranging from the synoptic scale down to the microscale (e.g., Whiteman et al. 2001; Zhong et al. 2001; Reeves and Stensrud 2009). Cold pools usually form during the night when the air near the surface cools in low wind speed conditions due to longwave radiation. Warming aloft due to mesoscale or synoptic-scale horizontal advection or subsidence often enhances the static stability. Weak surface heating in winter or due to clouds or fog can limit the growth of the daytime convective boundary layer and may prevent the mix 
out of the nighttime stable layer. Processes involved in the decay of the cold pool can include upper-level cold-air advection, bottom-up convective heating, top down shear-driven turbulent erosion, horizontal displacement, and airflow over the upstream topography (e.g., Whiteman et al. 2001; Zhong et al. 2001; Flamant et al. 2006; Lareau and Horel 2015; Haid et al. 2020).

The CRB in Washington and Oregon in the Pacific Northwest of the United States is often the scene of persistent cold pools in wintertime (Whiteman et al. 2001; Zhong et al. 2001; McCaffrey et al. 2019). They usually initiate when a high pressure system east of the Cascade Range (Fig. 1) promotes radiative cooling and easterly flow in the area. The easterly flow in the valley is blocked by the north-south-oriented Cascade Range, while the only outflow is directed through the narrow Columbia River Gorge (CRG). The cold air east of the Cascade Range enhances the large-scale pressure gradient, which often leads to a very strong gap flow through the gorge (Sharp and Mass 2002, 2004; Neiman et al. 2019). A rich dataset in the CRB area was collected during the Second Wind Forecast Improvement Project (WFIP2) from 2015 to 2017 (Wilczak et al. 2019), which allows for a detailed analysis of the cold pools and gap flows in the area. Using the WFIP2 dataset, McCaffrey et al. (2019) conducted a statistical analysis of cold-pool characteristics in the CRB, and Neiman et al. (2019) analyzed the gap flow through the CRG during two winter seasons with a focus on the gap-exit region.

In this study we present an observational case study of a 10day period (10-19 January 2017) during which a persistent cold pool and a strong gap flow formed. This period was classified by Neiman et al. (2019) as one of the strongest and longest gapflow events during the WFIP2 period with a total duration of $216 \mathrm{~h}$. In contrast to the statistical studies of McCaffrey et al. (2019) and Neiman et al. (2019), we focus on the processes relevant for the evolution of the cold pool and gap flow. The aims of this study are (i) to describe the spatial and temporal characteristics of the cold pool and gap flow during the formation, maintenance, and decay phases; and (ii) to identify the dominant physical processes associated with each of these phases. For the analysis, we used data from radar wind profilers (RWP) and associated radio acoustic sounding systems (RASS), microwave radiometers (MWR), and surface stations deployed within the WFIP2 project, which were complemented with several hundred surface stations available from the MesoWest repository and satellite data. To get the best possible information on the vertical thermodynamic structure in the CRB and in the gap-exit region of the CRG, we used an optimal estimation physical retrieval [i.e., Tropospheric Remotely Observed Profiling via Optimal Estimation (TROPoe)] to combine measurements from RASS, MWR, and surface measurements. This method reduces the limitations arising from the low vertical coverage of the RASS (the lowest measurement height is more than a hundred meters above the ground and the highest measurement height is often below $500 \mathrm{~m}$ during the cold-pool event) and the low vertical resolution of the MWR, which impacted the analyses of both McCaffrey et al. (2019) and Neiman et al. (2019).

The paper is structured as follows: section 2 describes the investigation area, observational datasets, and methods. Section 3 includes the temporal evolution of the conditions at two main sites west and east of the Cascade Range. In section 4, spatial characteristics and distinct processes during the different phases are investigated. Section 5 includes a discussion, followed by a summary and conclusions in section 6 .

\section{Investigation area, data, and methods}

The WFIP2 field campaign was conducted in the complex terrain of the CRB and the surrounding region (Fig. 1). To the west, the north-south-oriented Cascade Range presents a major barrier for easterly flow from the CRB, and the only outflow is through the narrow CRG that cuts through the range from west to east. The CRB can be separated into two main portions: a broad northern part and an elongated and narrow part (herein referred to as Columbia Valley), which extends more than $200 \mathrm{~km}$ east from the Cascade Range to the Horse Heaven Hills. The lowest part of the former is referred to as the Pasco subbasin (in Washington) and was the investigation area of the cold-pool studies by Whiteman et al. (2001) and Zhong et al. (2001). The valley floor is more confined in the western part of the Columbia Valley where it is only about $5 \mathrm{~km}$ wide with a distinct rim around $400 \mathrm{~m}$ above mean sea level (MSL) as compared with the eastern part where it is several tens of kilometers wide. To the south, the Columbia Valley is bordered by the Blue Mountains, which are part of the higher terrain of the Columbia Plateau. Several tributary rivers and associated valleys exist. These include the Deschutes Valley and the John Day Valley to the south of the Columbia Valley and the Yakima Valley in the north, which joins the Pasco subbasin. A large part of our analysis is based on measurements at two main sites, Troutdale, Oregon, at the gap-exit region of the CRG (station height $12 \mathrm{~m}$ MSL; square in Fig. 1) and Wasco (in Wasco County, Oregon) in the Columbia Valley in the CRB (station height $456 \mathrm{~m} \mathrm{MSL}$; star in Fig. 1). To characterize the terrain height in the $\mathrm{CRB}$, we estimated a mean ridge height of $1244 \mathrm{~m}$ MSL. For this purpose, we first determined the median terrain height (780 m MSL) in the area east of the Cascade Range (indicated by the black-outlined polygon in Fig. 1) and then calculated the mean terrain height of all pixels above this threshold.

\section{a. Instrumentation}

In the following, the instruments used in this study are described. A full list of the comprehensive instrumentation deployed during WFIP2 is given by Wilczak et al. (2019). One of the challenges we faced during the analysis of the presented cold-pool case study is the limited performance of many of the instruments during the harsh environmental conditions such as snow and ice on the radome of the MWR, limited vertical coverage of the RASS and RWP in the cold pool, and frozen in situ sensors on the surface towers. The first two limitations could be partly overcome by the application of TROPoe and the careful processing of the input data as described below.

\section{1) RWP/RASS}

We focused on the RWP/RASS at Troutdale and Wasco, but also incorporated data from the additional six RWP operated in the CRB (triangles in Fig. 1) in our analysis. The RWP/RASS 


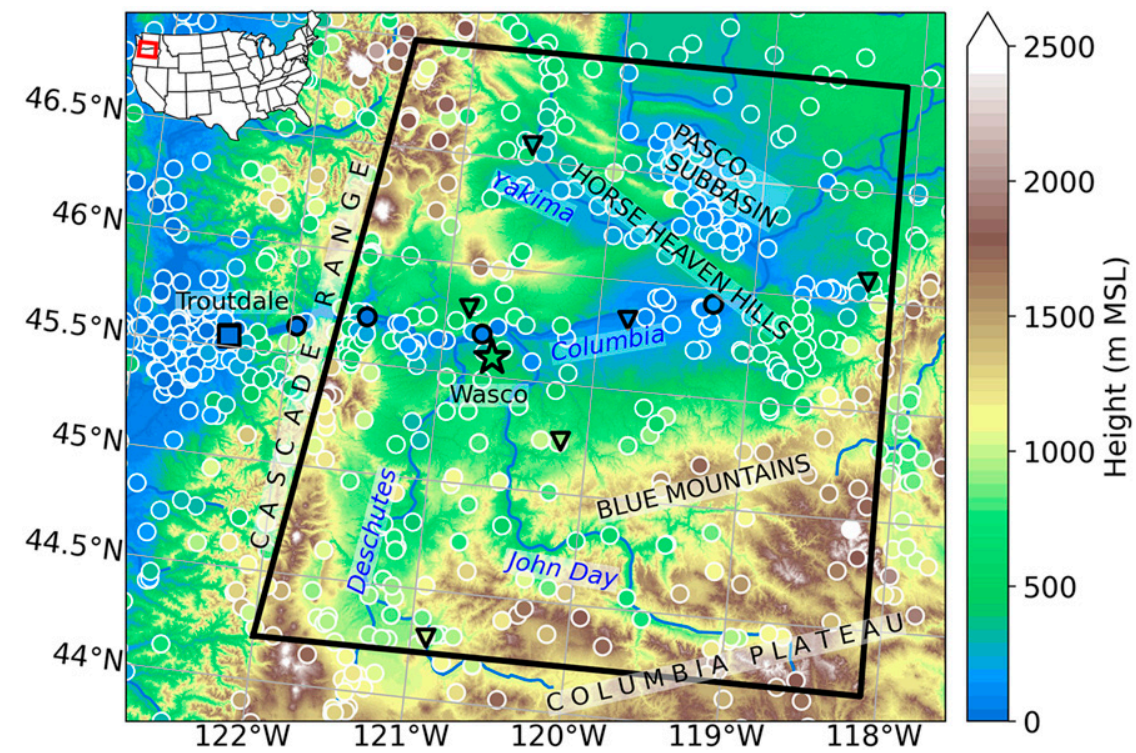

FIG. 1. Terrain height in the investigation area and location of surface stations from the WFIP2 campaign (black-outlined markers; circles indicate stations with surface measurements only, and triangles indicate stations where wind profiles from radar wind profilers were additionally available) and from the MesoWest repository (white-outlined circles). Profile information is used from the two main measurement sites at Troutdale (square) and Wasco (star) (for details on instrumentation, see the text). The fill color of each marker indicates the station height. Stations within the black-outlined polygon are considered to be in the CRB east of the Cascade Range. River names are given in blue. Terrain data are based on Shuttle Radar Topography Mission data with a resolution of 1 arc s. The inset plot in the upper-left corner shows the location of the investigation area in the United States.

at Troutdale and Wasco were 915-MHz systems (Carter et al. 1995), which were built within the Physical Science Laboratory at the National Oceanic and Atmospheric Administration (NOAA) with hardware similar to that of a Scintec LAP-3000 wind profiler, and provided horizontal wind and temperature profiles every hour. To assure high quality, the data were quality controlled for ground clutter (Jordan et al. 1997), radio frequency interference, intermittent hard targets (Bianco et al. 2013) and second trip echoes. In high-resolution (low resolution) mode, the RWP at Wasco measured winds between 81 and $2542 \mathrm{~m}$ above ground level (AGL) (187 and $6023 \mathrm{~m}$ AGL) from 24-min averages and the RWP at Troutdale measured winds between 138 and $2511 \mathrm{~m}$ AGL (145 and $6021 \mathrm{~m} \mathrm{AGL)}$ from 54-min averages, both with $57-\mathrm{m}(\approx 100 \mathrm{~m})$ vertical spacing. As the low-resolution mode had a larger vertical coverage, we used them to extend the high-resolution profiles for the analysis. Virtual temperature profiles from the RASS were available hourly between 120 and $1618 \mathrm{~m}$ AGL at Wasco and between 142 and $1581 \mathrm{~m} \mathrm{AGL}$ at Troutdale with around 60-m vertical spacing from 3-4-min averages. The different specifications arise because the RWP at Wasco was operated in a special mode described in McCaffrey et al. (2017) to derive turbulence dissipation rate for two 15 -min periods during the final $30 \mathrm{~min}$ of each hour.

\section{2) MWR}

Collocated with the RWP/RASS, two MWRs MP-3000A manufactured by Radiometrics (Solheim et al. 1998) were deployed at Troutdale and Wasco. Approximately every $2.5 \mathrm{~min}$, brightness temperature measurements at eight frequencies along the 22.2-GHz water vapor line and 14 frequencies along the $60-\mathrm{GHz}$ oxygen absorption band were available at $19.8^{\circ}$, $90^{\circ}$, and $160.2^{\circ}$ elevation angles. In addition, a vertical pointing KT15 radiometer manufactured by Heitronics measured brightness temperature in the infrared range, which is an indication of cloud-base temperature in the presence of clouds.

\section{3) Ceilometer}

Uncalibrated backscatter profiles with 10 -m vertical spacing and cloud-base heights retrieved with the manufacturer's algorithm were available at Wasco every $16 \mathrm{~s}$ from a CL31 ceilometer manufactured by Vaisala, Inc. For the analysis we used the lowest cloud-base height only. The manufacturer's algorithm failed to detect some low-level clouds on 15 January, which were evident from infrared temperature measurements and visible sky camera images. A cloud base is typically associated with a local maximum in the backscatter profile (e.g., Martucci et al. 2010). By detecting the lowest local maximum in the profiles, we were able to complement the automatically retrieved cloud-base heights and to improve the low-level cloud-base detection on 15 January.

\section{4) WFIP2 SURFACE STATIONS}

Near-surface measurements were conducted at 12 WFIP2 sites in the investigation area (markers with black outline in Fig. 1). Hourly averages of temperature and horizontal wind 
components from cup anemometers (with the time stamp at the end of each hour) were used for the analysis of spatial characteristics along with the surface stations from MesoWest. We additionally used net radiation directly measured at Troutdale and calculated from long- and shortwave radiation components at Wasco. Surface air pressure measured with high-precision microbarographs manufactured by Paroscientific at Troutdale and Wasco and averaged over 1-min intervals was used to determine the cross-Cascade pressure difference.

\section{5) MesoWest surface Stations}

To study the spatial structure of the near-surface temperature and wind, one-hour averaged temperature measurements from more than 700 stations distributed in the investigation area were used (circles with white outline in Fig. 1). Around 100 of these stations also reported horizontal wind. Nearly 400 stations with temperature measurements were located east of the Cascade Range (black-outlined polygon in Fig. 1) with about $14 \%$ located above the mean ridge height at $1244 \mathrm{~m}$ MSL. The data are available through MesoWest, which provides surface observations from many different organizations (Horel et al. 2002) and can be downloaded with Mesonet API (Synoptic Data 2021). We used all stations available in the investigation area, which include stations operated for agricultural, air quality, hydrological, fire weather, road weather, and research and education purposes and stations from federal, state, and local networks and from the Citizen Weather Observer Program (CWOP). We applied the automatic quality check provided by Synoptic Data, which includes checks for plausible range, large jumps from one time stamp to the next, consistency in space and time between neighboring stations, and the removal of sequences of unchanging values. Because some questionable values remained, we removed in a second even more strict step stations that reported data less than $50 \%$ of the time during the investigated 10-day period or showed strong differences to neighboring stations in a visual inspection.

\section{b. Methods}

\section{1) OPTIMAL ESTIMATION PHYSICAL RETRIEVAL (TROPOE)}

To obtain the best possible information on thermodynamic profiles in the troposphere from the measurements, we used the optimal estimation physical retrieval TROPoe. The retrieval algorithm was originally developed for Atmospheric Emitted Radiance Interferometer (AERI) measurements (Turner and Löhnert 2014) and was modified and improved to work with additional observations such as MWR, surface station, and Raman lidar measurements (Turner and Blumberg 2019). The goal of this retrieval is to determine the optimal state vector, which consists of thermodynamic profiles and cloud properties and satisfies both the observations and the climatological information (the prior). The latter is needed to constrain the retrieval to realistic solutions and is based on radiosonde data. Starting with the prior as a first guess of the state vector a forward model such as an infrared or microwave radiative transfer model is used to compute brightness temperatures. This process is iteratively repeated until the computed values and the observed values agree within the uncertainty of the measurements. Uncertainties in the observations, the forward model, and the prior are propagated and characterized by the posterior covariance matrix. Djalalova et al. (2021, manuscript submitted to Atmos. Meas. Tech.) compared different configurations of TROPoe, that is, including surface, MWR, and RASS data, with temperature profiles obtained with the manufacturer's neural network retrieval and radio soundings and found that when adding the RASS data the TROPoe profiles more accurately represent low-level temperature inversions and better match the radio soundings up to $5 \mathrm{~km}$, that is, much above the actual coverage of the RASS data.

In this study, we incorporated measurements from the RASS, MWR, and surface stations at Troutdale and Wasco in TROPoe to retrieve temperature and humidity profiles and liquid water path (LWP). Monthly priors were constructed based on operational radio soundings: as the conditions west and east of the Cascade Range may strongly differ, we used radio soundings at Salem, Oregon (about $80 \mathrm{~km}$ southwest of Troutdale) for Troutdale, and radio soundings at Spokane, Washington (in the northern part of the CRB) for Wasco. TROPoe profiles were calculated every $15 \mathrm{~min}$ using MWR brightness temperature measurements at all three elevation angles and surface measurements of air temperature, humidity and pressure averaged over a 15-min centered window and linearly interpolated in time RASS virtual temperature profiles. For Wasco, the ceilometer cloud-base heights were included in the retrieval. It turned out that unrealistic fluctuations from one retrieved thermodynamic profile to the next occurred depending on the vertical coverage of the RASS profiles. This was in particular a problem at Wasco when the cold pool was well established, which strongly limited the RASS vertical coverage. To reduce this impact and to make the vertical coverage more constant from one profile to the other, we postprocessed the RASS temperatures at Wasco between 12 and 16 January before running TROPoe. Temperature values at a specific range gate were linearly interpolated in time if the temporal gap was less than $6 \mathrm{~h}$ at this range gate and the temperature before and after the gap differed by less than $1 \mathrm{~K}$. This increased the RASS data availability between 350 and $500 \mathrm{~m}$ AGL by around $35 \%$.

The brightness temperatures measured by the MWR are strongly influenced by water or ice on the radome that may lead to erroneous measurements during and after precipitation. To identify periods with precipitation, we used the rangecorrected signal-to-noise ratio (rc SNR) from the RWP that is enhanced during precipitation because the effective scattering cross section of hydrometeors is larger than that for the index-of-refraction fluctuations in the atmosphere. Periods during which the rc SNR was larger than $60 \mathrm{~dB}$ in more than one-half of the range gates were flagged (about $13 \%$ at Wasco and about $18 \%$ at Troutdale).

After the passage of a warm front on 18 January, drifting and falling snow stuck to the top and windward side of the MWR radome, which affected the measured brightness temperatures and prevented realistic TROPoe retrievals on 18 January. The brightness temperatures measured at the sheltered downward side of the radome still seemed to be unaffected, and so TROPoe was run using only those brightness temperatures. 


\section{2) LONGWAVE HEATING RATE PROFILES}

A rapid radiative transfer model (Mlawer et al. 1997) was used to calculate profiles of nighttime longwave heating rates from the TROPoe thermodynamic profiles at Wasco. The model requires information on the vertical distribution of liquid water, and we estimated liquid water content profiles using cloud-base height from the ceilometer and LWP from TROPoe. Another input parameter is skin temperature, which was not directly measured at Wasco and that we estimated from the longwave upward radiation using the Stefan-Boltzmann law with a emissivity of 0.985 , which is within the range of values reported for snow (e.g., Shea and Jamieson 2011).

\section{3) DETECTION OF LOW-LEVEL CLOUD TOPS IN SATELLITE IMAGES}

Spatial information on clouds is available from the Geostationary Operational Environmental Satellites (GOES) Solar Insolation Product (GSIP); data are provided hourly with 4$\mathrm{km}$ horizontal resolution and can be downloaded from the NOAA Comprehensive Large Array-data Stewardship System (CLASS). From the LWP measurements by the MWR and visible sky camera observations, we knew that the low-level clouds which formed in the CRB during the cold pool were relatively thin (a few hundred meters at the most), so that the cloud top was still within the cold pool in the lower troposphere. In contrast, the cloud-top heights available in the GSIP data ranged throughout the midtroposphere, likely because the temperature structure in the deep and strong cold pool was not correctly represented in the satellite automated cloud-height retrieval algorithm. Because of this we did not use the automated cloud-top heights available in the GSIP data for the detection of low-level cloud tops, but instead developed an alternate method.

For cloudy pixels, cloud-top temperature is available in the GSIP data. As air temperature usually decreases throughout the troposphere, the cloud-top temperature of low-level clouds is typically warmer than the one of mid- and high-level clouds. By comparing cloud-top temperature from the satellite images at the pixel closest to Wasco with the infrared temperature measurements from the MWR and the ceilometer measurements, we found that low-level clouds at Wasco were usually associated with cloud-top temperatures warmer than $250 \mathrm{~K}$. We hence used a threshold of $250 \mathrm{~K}$ to distinguish between low clouds (top warmer than $250 \mathrm{~K}$ ) and mid- or high-level clouds (tops colder than $250 \mathrm{~K}$ ) in the satellite images. To assess the duration of low-level cloud coverage during different nighttime periods, we then determined for each pixel on how many of the hours the cloud top was warmer than $250 \mathrm{~K}$. Because mid- or high-level clouds prevent the detection of low-level clouds and to reduce the risk of misinterpretation, a pixel was flagged if the cloud-top temperature at this pixel was colder than $250 \mathrm{~K}$ for more than one-half of the time period.

\section{Temporal evolution of atmospheric conditions at Troutdale and Wasco}

In this section, we describe the atmospheric conditions at the two main sites, that is, Troutdale at the gap-exit region of the CRG and Wasco in the Columbia Valley, during the 10-day period from 10 to 19 January and link them to the synopticscale patterns. To illustrate the synoptic-scale conditions, we use surface and $850-\mathrm{hPa}$ analyses (Fig. 2). The latter represents the conditions at around $1500 \mathrm{~m} \mathrm{MSL}$, that is, just above the mean ridge height. Based on the temperature evolution at Wasco, we separated the period into three main phases: phase 1 describes the period prior to the cold-pool formation in the CRB, phase 2 comprises the period when a persistent cold pool formed and was maintained, and phase 3 covers the decay of the cold pool the beginning of which was defined as the time when the bottom of the elevated inversion (i.e., the bottom of the layer in which temperature increases) started to descend. The three phases are indicated in Fig. 3, which provides an overview of the temporal evolution of the cold pool and gap flow through time-height cross sections of temperature and wind. Figure 4 displays temperature, humidity, and wind at selected heights for a more detailed view, as well as radiation and pressure measurements.

\section{a. Period prior to the cold pool in the CRB (phase 1)}

At the beginning of phase 1, a shallow surface temperature inversion of a few hundred meters depth existed at Troutdale and Wasco (Figs. 3a,b and 4a,b). The wind was mainly coming from the southwest, except for the lowest layers at Troutdale (Figs. 3c,d and 4c-f). In the course of the day, strong synoptically driven easterly flow became established. It started out shallow and quickly rose to around $1500-\mathrm{m}$ depth at both Troutdale and Wasco, bringing cooler air with it (Figs. 3 and $4 \mathrm{a}-\mathrm{f}$ ). The strong easterly flow and the rapid deepening can be traced to the synoptic flow. On the afternoon of 10 January, the large-scale pressure gradient that formed between a surface low over the Pacific coast and a high pressure system inland supported easterly flow in the CRB (Fig. 2a). In a rather unusual synoptic setting, a secondary cold front was present to the north and east of the main low center at the coast, with colder air dropping into the CRB with a northerly component to the wind. This period was identified by Neiman et al. (2019) as the heaviest snowstorm since 2008 in the Portland area west of the CRG. The maximum wind speed reached $19 \mathrm{~m} \mathrm{~s}^{-1}$ at Wasco and $22 \mathrm{~m} \mathrm{~s}^{-1}$ at Troutdale (Figs. 3c,d) and occurred simultaneously with the maximum cross-Cascade pressure difference on the evening of 10 January (Fig. 4j). The maximum depth of the easterly flow layer at both Wasco and Troutdale was reached at around 0000 Pacific standard time (PST) 11 January (Figs. 3c,d), right before the surface pressure started to increase (Fig. 4i). After that, the easterly flow weakened, and its depth gradually decreased to around $700-800 \mathrm{~m}$ at both sites in the afternoon of 11 January (Figs. 3c,d). The deceleration of the flow was associated with a weakening of the synoptically driven cross-Cascade pressure difference on the morning of 11 January (Fig. 4j). Despite the weakened pressure difference, a gap flow of around 600-m depth persisted at Troutdale during the remainder of phase 1 and during phase 2 (Fig. 3c).

During the portion of phase 1 with strong easterly wind, the air generally cooled at Troutdale and Wasco, although the cooling was much stronger at Wasco, dropping nearly $10^{\circ} \mathrm{C}$ (Figs. 3a,b and 4a,b). After the passage of the snowstorm and 

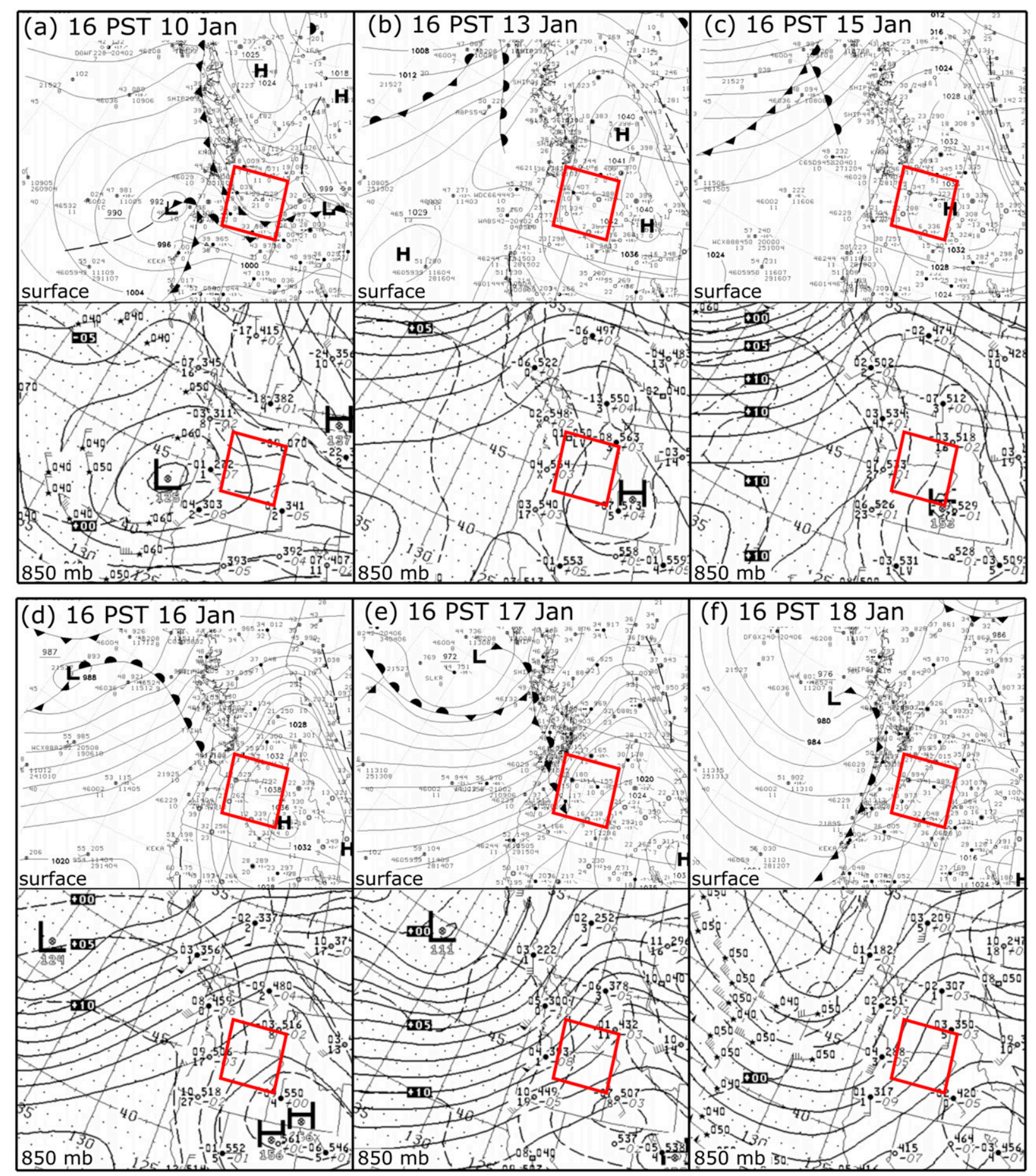

FIG. 2. Surface analyses and Global Forecast System 850-hPa analyses from the Weather Prediction Center at 1600 PST (a) 10, (b) 13, (c) 15, (d) 16, (e) 17, and (f) 18 Jan. The red-outlined rectangle marks the approximate location of the investigation area.

with temperatures below freezing, the ground was likely snowcovered at many locations throughout the area, which could be confirmed for Wasco by sky camera images. Starting on 11 January, a surface high began to build and dropped southward with the center being located close to the CRB after the afternoon of 12 January (Fig. 2b). With mainly clear skies (indicated by the low infrared brightness temperature in Fig. 4h) and weak wind in low layers (Figs. 3d and 4d), negative net radiation was large (Fig. $4 \mathrm{~h}$ ) and resulted in the formation of a shallow surface inversion at Wasco during the night from 

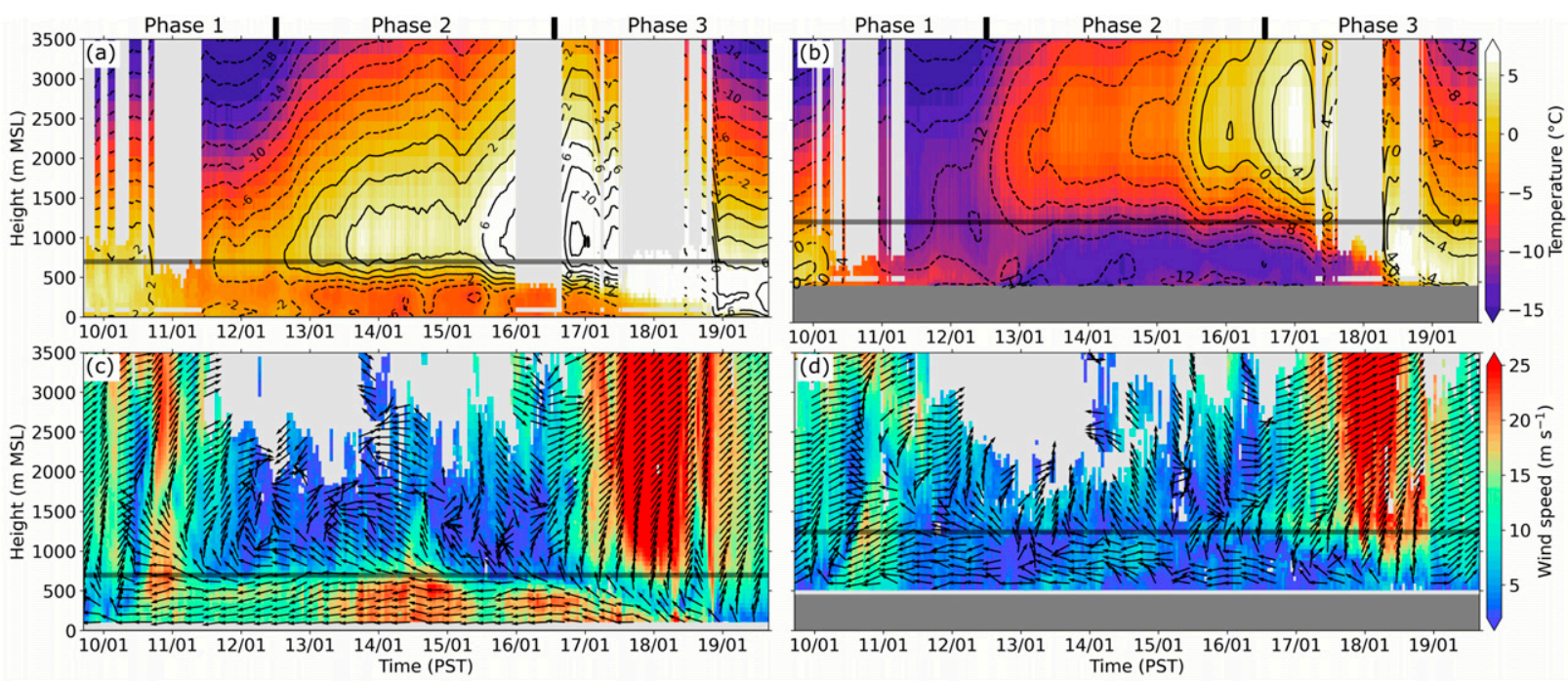

FIG. 3. Temporal evolution of temperature profiles retrieved with TROPoe at (a) Troutdale and (b) Wasco and of horizontal wind speed (color coded) and wind direction (normalized arrows) measured with the RWP at (c) Troutdale and (d) Wasco. Missing values appear in light gray, terrain height is indicated by the dark-gray shading, and the horizontal line shows the height of the inner gorge sidewalls at Troutdale and the mean ridge height east of the Cascade Range at Wasco. During periods when TROPoe retrievals are not available, temperature measurements from RASS and surface stations are added in (a) and (b).

11 to 12 January, which was eroded again during daytime on 12 January (Figs. 3b and 4b).

\section{b. Persistent cold pool in the CRB and gap flow (phase 2)}

On 12 January, warming above around $1200 \mathrm{~m}$ MSL started at Wasco that initiated the formation of a cold pool and marked the beginning of phase 2 (Figs. 3a,b and 4a,b). Strong negative net radiation in the cloud-free first half of the night from 12 to 13 January (Fig. 4h) quickly enhanced the temperature inversion at Wasco (Figs. $3 b$ and $4 b$ ). In general, a layered structure was visible within the cold pool throughout phase 2: the lowest layer of a few hundred meters depth exhibited a diurnal cycle with the formation of a surface inversion during nighttime and a convective boundary layer during daytime (most easily seen in the blue and orange curves in Fig. 4b). Except for this lowest layer, the stratification in the lower $1200 \mathrm{~m}$ MSL, that is, below the mean ridge height, was near isothermal and experienced little variability in time (Fig. 3b). The near-isothermal layer was topped by a strong elevated inversion in which temperature increased by around $6^{\circ} \mathrm{C}$ up to around $2000 \mathrm{~m}$ MSL. The inversion is capped by another near-isothermal layer up to around $3000 \mathrm{~m}$ MSL. This vertical structure of the cold pool resembles the cold-pool structures in the Pasco subbasin described by Whiteman et al. (2001) and Zhong et al. (2001). Below the mean ridge height, weak $\left(<5 \mathrm{~m} \mathrm{~s}^{-1}\right)$ easterly flow prevailed, while the flow above was more variable in direction (Figs. $3 d$ and $4 d, f$ ). The top of this layer with easterly flow was rather homogeneous in height relative to mean sea level throughout the basin, as evident from RWP measurements throughout the CRB (not shown; RWP site locations in Fig. 1). Daytime net radiation was generally below $50 \mathrm{~W} \mathrm{~m}^{-2}$, and surface sensible heat flux was below $30 \mathrm{~W} \mathrm{~m}^{-2}$ (Fig. 4h). This can be explained by the high albedo of the snow-covered frozen ground and the frequent presence of low-level clouds (indicated by small negative net radiation and high infrared brightness temperatures in Fig. 4h) and agrees with the seasonal analysis of the surface energy balance in the CRB by Grachev et al. (2020). Friction velocity was correlated with wind speed and was small $\left(<0.3 \mathrm{~m} \mathrm{~s}^{-1}\right)$ during the cold pool (Fig. 4d). The warming aloft stopped on 13 January and a mixture between daytime warming in the convective boundary layer and reduced radiative cooling during nighttime due to the presence of low-level clouds likely inhibited a further cooling of the near-surface layer and the temperature difference between the cold air below the mean ridge height and the warm air aloft did not change much until 15 January (Figs. 3b and 4b).

At Troutdale, the air also warmed above approximately $700 \mathrm{~m}$ MSL under the high-pressure influence, leading to a strong temperature inversion (around $8^{\circ} \mathrm{C}$ ) capping the gap flow (Figs. 3a,c and 4a,c,e). Diurnal temperature variations in the gap flow were small and the capping inversion was quite constant in time and strength. No convective boundary layer formed (Fig. 4a) despite high positive net radiation in the cloud-free daytime conditions (Fig. 4g). While the gap-flow depth was fairly constant at around $600 \mathrm{~m}$, the gap flow reached its maximum strength of approximately $25 \mathrm{~m} \mathrm{~s}^{-1}$ on 14 January (Fig. 3c), which coincided with the maximum cross-Cascade pressure difference (Fig. 4j). The gap-flow depth was very close to the average depth of $570 \mathrm{~m}$ MSL identified by Neiman et al. (2019) for a two-season statistic and was below the top of the inner gorge sidewall at $700 \mathrm{~m}$ MSL.

On 15 January, the synoptic-scale pressure pattern had not changed much, but temperature at $850 \mathrm{hPa}$ had increased in the wider area as visible in the $5^{\circ} \mathrm{C}$ isotherm that was then located at the coast (Fig. 2c) as compared with its location offshore on 13 January (Fig. 2b). While wind speed aloft was 

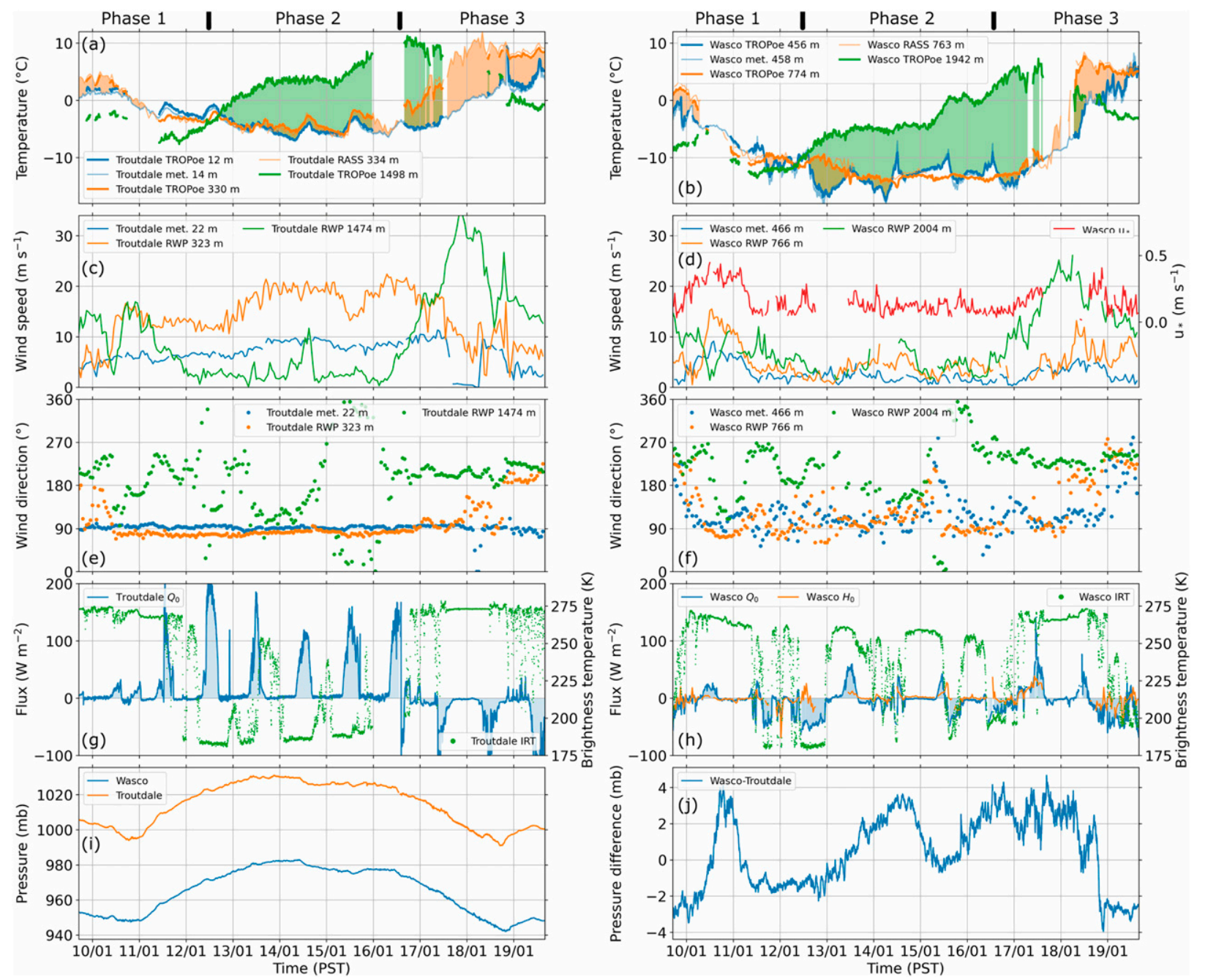

FIG. 4. Time series of temperature measured near the surface and with RASS and retrieved with TROPoe for (a) Troutdale and (b) Wasco. Wind speed and wind direction measured near the surface and with RWP at different heights above mean sea level for (c),(e) Troutdale and (d),(f) Wasco. In (d), friction velocity $u_{*}$ is additionally shown. Net radiation $Q_{0}$ and infrared brightness temperature IRT for (g) Troutdale and (h) Wasco. Also shown in (h) is sensible heat flux $H_{0}$. (i) Surface pressure at Wasco and Troutdale, and (j) surface pressure difference between Wasco and Troutdale. To account for the station height difference, the mean pressure value for the whole time period was subtracted from the pressure values at the respective sites before calculating the difference in $(\mathrm{j})$.

still weak at Troutdale and Wasco, the flow gained a northerly component and temperature above the cold pool at Wasco and above the gap flow at Troutdale increased (Figs. 3 and 4a-f). This upper-level warming increased the elevated temperature inversion above the mean ridge height at Wasco to nearly $15^{\circ} \mathrm{C}$ over $\sim 1000 \mathrm{~m}$.

\section{c. Decay of the cold pool (phase 3)}

On 16 January, the surface high pressure system migrated farther to the southeast and an Aleutian low moved south toward the Pacific Northwest (Fig. 2d,e). This synoptic pattern resulted in a strong pressure gradient at $850 \mathrm{hPa}$ associated with very strong southwesterly flow bringing warmer air over the investigation area.
Between the evening of 17 January and noon on 18 January a warm front with precipitation passed the area (Fig. 2e), during which wind speed in the southwesterly flow aloft was more than $30 \mathrm{~m} \mathrm{~s}^{-1}$ on the evening of 17 January (Figs. 3c,d). The precipitation inhibited the retrieval of temperature profiles with TROPoe during and after the frontal passage. The warm and strong southwesterly flow gradually descended on 17 and 18 January, decreasing the depth of the layer with cold air and easterly flow at Wasco and the gap-flow depth at Troutdale (Fig. 3). This resulted in a very strong shallow inversion with a temperature increase of around $15^{\circ} \mathrm{C}$ in the lowest few hundred meters at Wasco around noon on 18 January (best visible in the orange shading in Fig. 4b). Starting on 17 January, the nearsurface layer continuously warmed at both sites, which slowly 

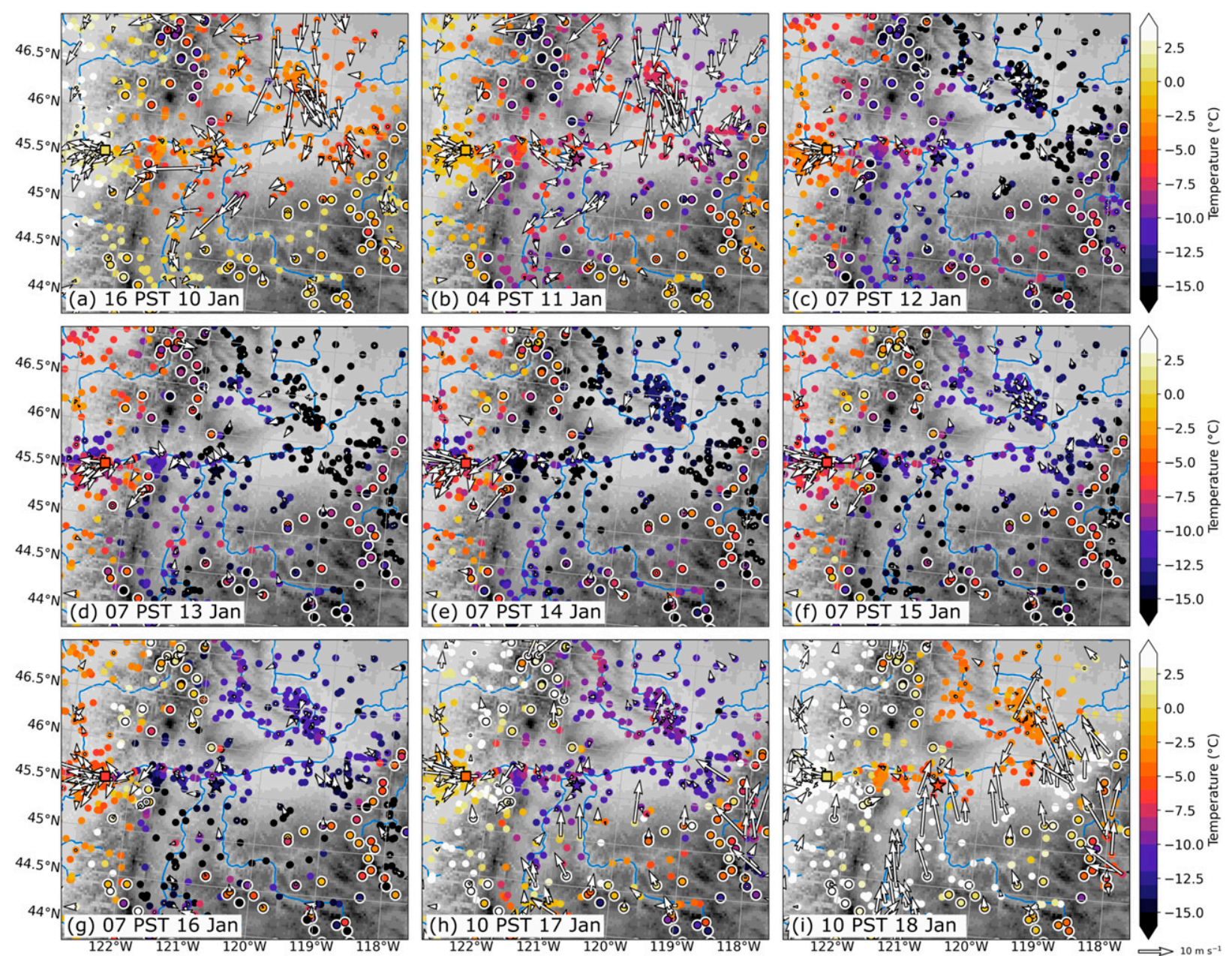

FIG. 5. Spatial distribution of near-surface temperature (color coded) and horizontal wind vector (arrows) from the surface stations. The locations of Troutdale and Wasco are indicated by the square and star, respectively. White-black outlines mark stations located above the mean ridge height. Gray shading shows terrain height, and rivers are indicated in blue.

weakened the surface inversion and eventually eroded the cold pool at Wasco on 19 January.

During the night from 18 to 19 January, an occlusion passed the investigation area from west to east (Fig. 2f) with a minimum in pressure occurring shortly before midnight first at Troutdale and then at Wasco, which led to a rapid decrease in the cross-Cascade pressure difference (Figs. 4i,j). The rapid decrease in pressure difference marked the end of easterly flow in the CRB and the gap flow at Troutdale, except for the nearsurface layer at Troutdale where weak easterly wind persisted (Figs. 4c-f). The relationship between pressure difference and gap flow is in agreement with the composite analysis of Neiman et al. (2019).

\section{Spatial characteristics and distinct processes during the different phases}

In the previous section, we described the evolution of surface conditions and temperature and horizontal wind profiles at the two main sites Troutdale and Wasco during the 10-day period. In this section, we extend our analysis from these point measurements to the spatial distribution by using measurements of near-surface temperature and horizontal wind as well as satellite data.

\section{a. Spatiotemporal evolution of temperature and wind during the evolution and maintenance of the cold pool}

To study the temporal evolution of the temperature and wind distribution, we show a series of spatial maps during the different phases (Fig. 5). The near-surface wind field during phase 1 was a result of the synoptic-scale conditions and the impact of the terrain (Figs. 5a,b). The higher altitude stations in the northern part of the Cascade Range measured easterly flow and the stations on the Horse Heaven Hills separating the Pasco subbasin from the Columbia Valley observed a strong northerly component. This is in line with the location of the cold front in the afternoon of 10 January (Fig. 2a). At the lower altitude stations the influence of the terrain on the flow was visible (Figs. 5a,b). The northerly flow in the Pasco subbasin was deflected to the east by the higher terrain of the Horse 


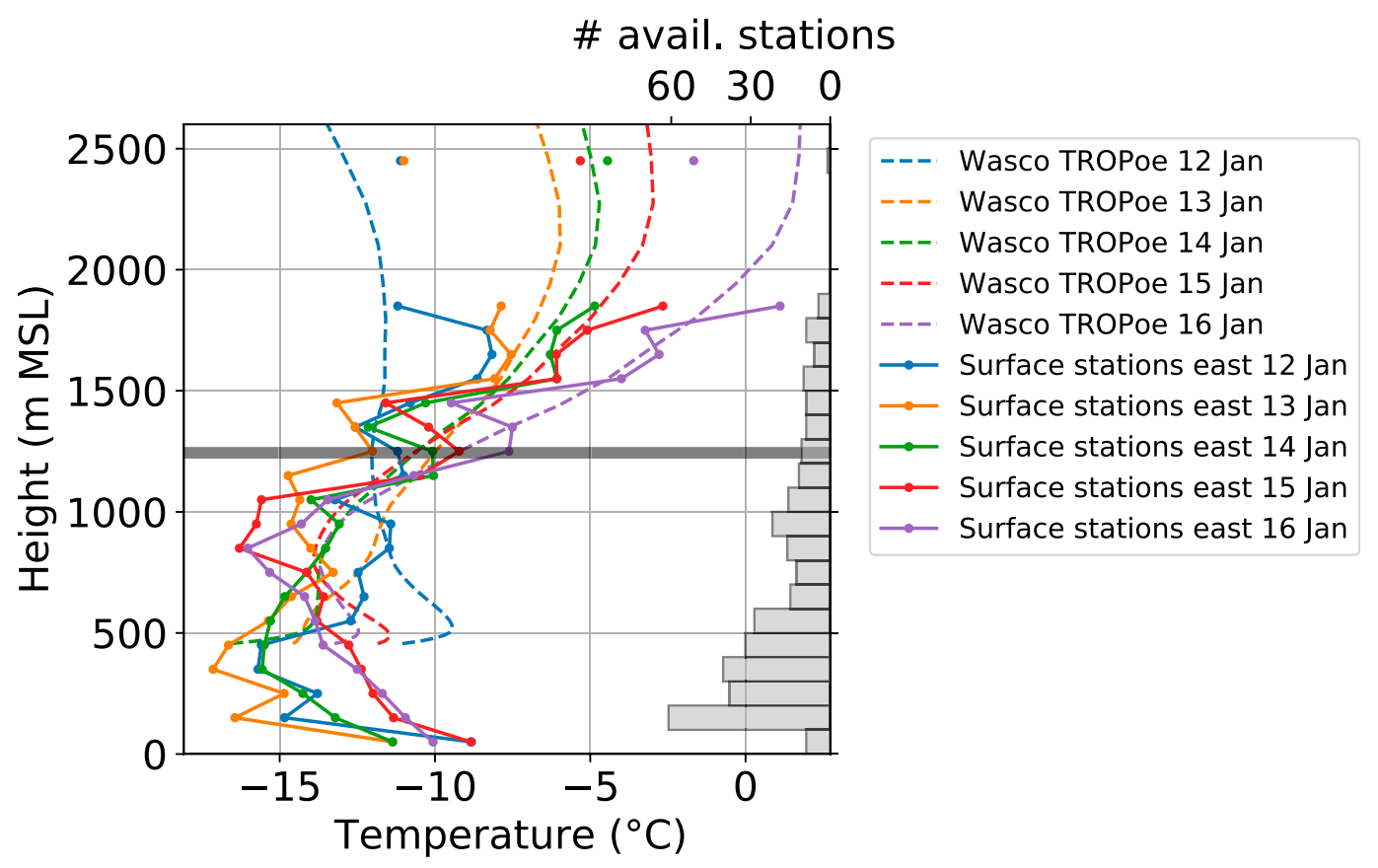

FIG. 6. Temperature profiles at Wasco retrieved with TROPoe (dashed) and pseudovertical temperature profiles (solid) from the surface stations east of the Cascade Range (area indicated by the black-outlined polygon in Fig. 1) at 0700 PST from 12 to $16 \mathrm{Jan}$. The pseudovertical temperature profiles are calculated for $100-\mathrm{m}$ height bins. Gray horizontal bars give the number of stations in the respective height bin. The horizontal line marks the mean ridge height.

Heaven Hills and the flow in the Columbia Valley and the Deschutes Valley followed the valley axes that resulted in mainly easterly and northerly flow, respectively. The easterly flow through the CRG widened west of the gorge where the terrain is less confined. During the night from 10 to 11 January, temperature decreased at all stations throughout the area (Figs. 5a,b) in agreement with the observations at Troutdale and Wasco (Figs. 3a,b and 4a,b). The cooling was less pronounced on the higher terrain of the Columbia Plateau.

Figures $5 \mathrm{c}-\mathrm{g}$ illustrate the temperature and wind field at 0700 PST from 12 to 17 January, that is, during phase 2. The time at the end of the night before sunrise was chosen as the temperatures at the individual stations were not influenced by daytime heating, which allowed for us to study the spatial structure and day-to-day variability of the cold pool. Once the area came under the influence of the evolving surface high on 11 January, wind speed weakened throughout the CRB to a few meters per second, and temperatures dropped at the lower altitude stations (Fig. 5c). During the following five days and nights, the cold air filling the valleys and basins of the CRB was maintained. However, the regions where the coldest nearsurface temperatures occurred varied. On the mornings of the 12 and 13 January, the coldest temperatures occurred in the eastern part of the Columbia Valley and in the Pasco subbasin with values well below $-20^{\circ} \mathrm{C}$ (Figs. 5 c,d). On the mornings of 15 and 16 January, the coldest near-surface temperatures occurred on the slopes of the Blue Mountains and in the Deschutes Valley, despite its elevated valley floor (Figs. 5f,g). This variability in near-surface temperature will be investigated in detail in section $4 \mathrm{~b}$.
In the exit region of the CRG, the easterly wind remained strong during phase 2 in agreement with the gap flow found in the profile measurements at Troutdale (Fig. 3c). The gap flow brought cold air from the $\mathrm{CRB}$ into the region west of the Cascade Range. Wind measurements in the exit region indicate that the gap flow was diverted to the south, which was also found in model simulations by Sharp and Mass (2002). Interestingly, the coldest temperatures in the morning were measured not in the area with the strongest outflow, but slightly to the north of it (Figs. 5d-f). One possible explanation could be that the downward mixing of warmer air due to shear-generated turbulence was stronger in the areas with stronger gap flow, thus leading to higher near-surface temperatures during the night - a process also suggested by Sharp and Mass (2002) and Sharp and Mass (2004).

To get a better view of the change of near-surface temperature with station height in the CRB during the persistent cold-pool period, pseudovertical profiles of temperature were calculated from the surface measurements. Whiteman and Hoch (2014) compared such pseudovertical temperature profiles with radiosonde measurements in the broad Salt Lake Valley, Utah, and found that these profiles are suitable proxies for the free-air temperature structure-in particular during wintertime. Pseudovertical temperature profiles were calculated for all surface stations east of the Cascade Range (black-outlined polygon in Fig. 1), that is, in an area of approximately $300 \mathrm{~km} \times$ $300 \mathrm{~km}$ size. Despite the large area considered, there is good agreement between the pseudovertical profiles and the temperature profiles retrieved with TROPoe at Wasco (Fig. 6). Above the mean ridge height, both types of profiles reflect the 


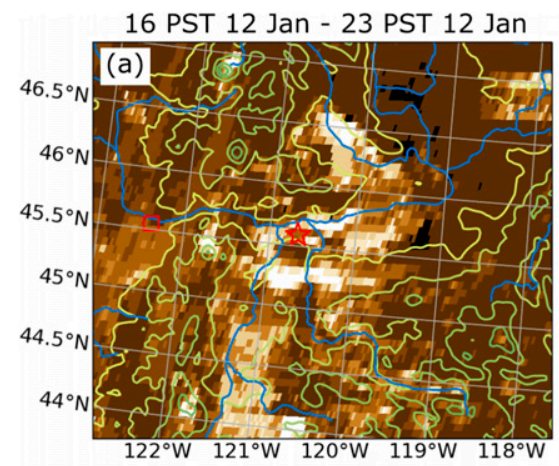

00 PST 13 Jan - 07 PST 13 Jan
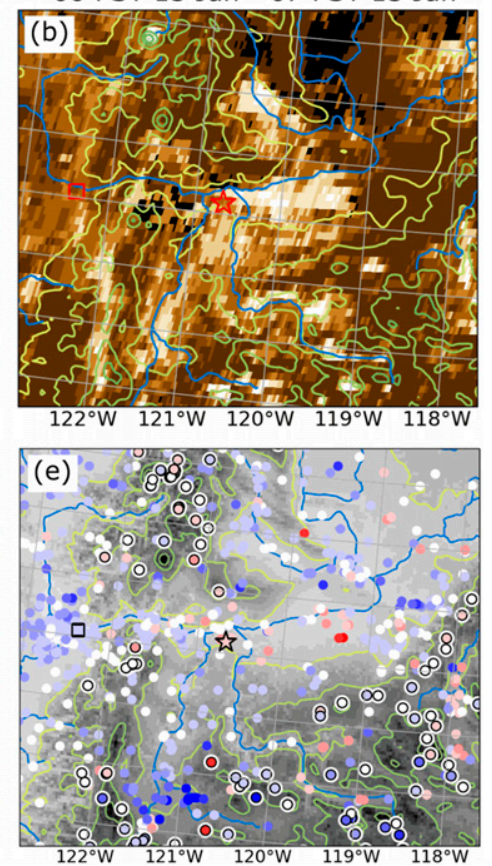

16 PST 15 Jan - 07 PST 16 Jan
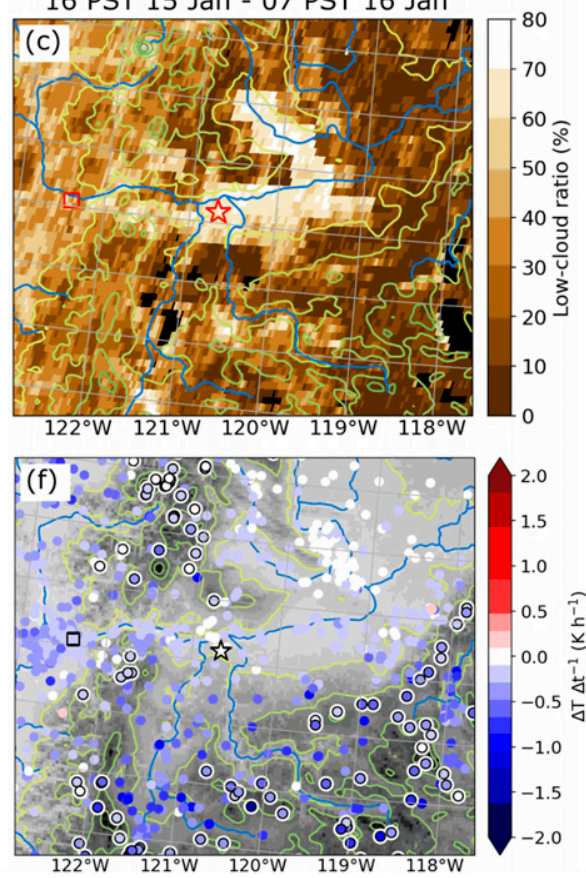

FIG. 7. (a)-(c) Spatial distribution of the percentage of hours during which low-level cloud tops were detected by the satellite, and (d)-(f) near-surface temperature change at the surface stations during different time periods (indicated at the top of each column). Pixels at which mid- or high-level clouds were present during more than one-half of the time period are masked in black in (a)-(c). The locations of Troutdale and Wasco are indicated by the square and star, respectively. White-black outlines in (d)-(f) mark stations located above the mean ridge height. Gray shading [in (d)-(f)] and contours show terrain height (contour values increase from yellow to green in 500-m intervals), and rivers are indicated in blue.

evolution of the strong elevated temperature inversion in time (around $15^{\circ} \mathrm{C}$ over $1000 \mathrm{~m}$ on 16 January). The pseudovertical temperature profile showed little change with height below the mean ridge height on 12-14 January. On 15 and 16 January, the temperature from the pseudovertical profiles increased in the lowest few hundred meters and decreased above. This can be explained by the overall warmer temperature in the Columbia Valley (stations mainly below $400 \mathrm{~m}$ MSL) and the colder temperatures on the slopes of the Blue Mountains and in the Deschutes Valley with its higher floor elevation (Figs. 5f,g). The surface stations contributing to the pseudovertical profiles above mean ridge height are spread throughout the whole area (stations with white-black outlines in Fig. 5). The fact that the resulting pseudovertical temperature inversion agrees well with the profiles at Wasco in the center of the area indicates that the elevated temperature inversion was quite horizontally homogeneous and affected a large area east of the Cascade Range.

\section{b. Impact of fog and low-level clouds on the cold-pool structure}

1) RELATIONSHIP BETWEEN NEAR-SURFACE TEMPERATURE AND LOW-LEVEL CLOUD COVERAGE

The measurements at Wasco revealed that the diurnal nearsurface temperature oscillation was dampened in the presence of low-level clouds (Figs. 4b,h), as they block solar radiation and thus reduce surface heating and diminish the amount of longwave radiation that escapes from the atmosphere below the clouds. To investigate the relationship between nearsurface temperature and low-level clouds for the whole CRB, we compared low-level cloud coverage determined from satellite images with nighttime cooling rates at the surface stations (Fig. 7). During the first half of the night from 12 to 13 January, low-level clouds were scattered in the CRB (Fig. 7a). Areas with clouds, for example, in the Yakima Valley, in the Deschutes Valley, and in parts of the Columbia Valley, generally cooled slowly $\left(>-0.5 \mathrm{~K} \mathrm{~h}^{-1}\right)$ (Fig. 7d). Cloud-free areas, for example, around Wasco and in the eastern part of the Columbia Valley and the Pasco subbasin, overall revealed cooling rates of more than $0.5 \mathrm{~K} \mathrm{~h}^{-1}$. During the second half of the night, many of the stations in the center part of the Columbia Valley and in the Yakima Valley measured a temperature increase (Fig. 7e). This again can be linked to a high value of low-level cloud-cover in these areas (Fig. 7b). The Columbia Valley and the Yakima Valley were filled by lowlevel clouds on the night from 15 to 16 January (Fig. 7c). This was associated with weak cooling or even heating near the surface (Fig. 7f). The stronger cooling in the mainly cloud-free Deschutes Valley (Figs. 7c,f) lowered the near-surface temperature making it the coldest location throughout the basin in the morning of 16 January (Fig. 5g). Mid- or high-level clouds were present in large parts of the investigation area during most of the night from 13 to 14 January and more than half of the night from 14 to 15 January, preventing the detection of 


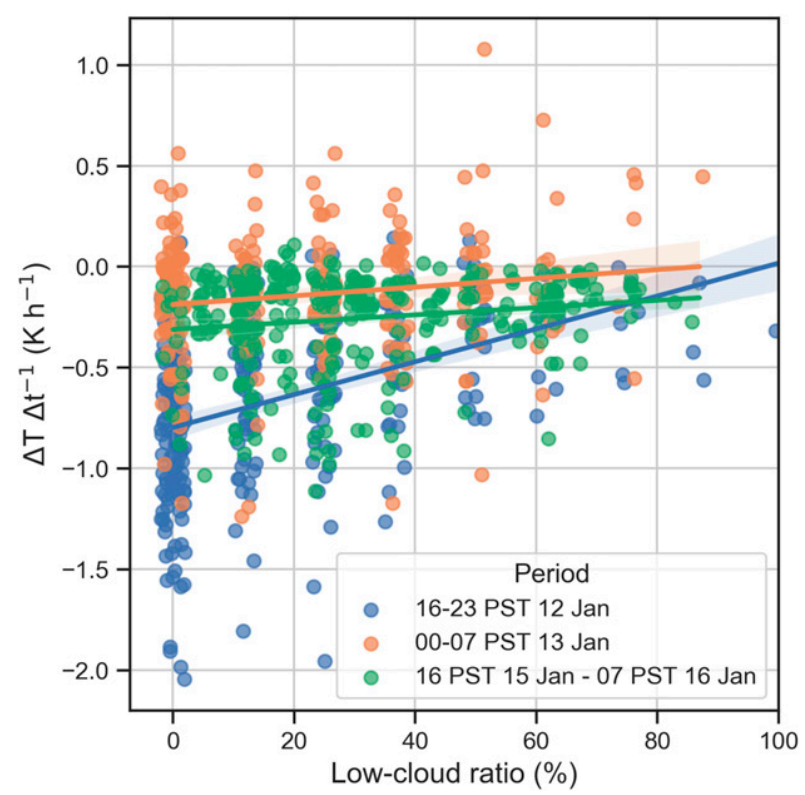

FIG. 8. Relationship between nighttime temperature change and low-cloud ratio at the closest satellite pixel at stations located below the mean ridge height east of the Cascade Range. The straight lines indicate the line of best fit for the different nighttime periods.

potential low-level clouds. During the few hours when mid- or high-level clouds were absent during the night from 14 to 15 January, the satellite images revealed that the Columbia Valley and the Yakima Valley were filled by low-level clouds similar to the pattern found during the night from 15 to 16 January (Fig. 7c). This is consistent with the high infrared brightness temperatures and low net radiation observed at Wasco during this night (Fig. 4h) and also fits the weak cooling or even heating reported by the near-surface stations in these areas (not shown). The relationship between nocturnal near-surface temperature changes and low-level clouds is not always unambiguous. For example, some parts of the Pasco subbasin remained largely cloud-free throughout the night from 12 to 13 January (Figs. 7a,b). The observed temperature decrease at many stations was, however, much stronger during the first half of the night than during the second half (Figs. 7d,e). During the night from 15 to 16 January, nearsurface temperature in the Pasco subbasin hardly changed although the area was mainly cloud free (Figs. 7c,f).

For a more quantitative analysis of low-cloud ratio and nocturnal temperature changes, we related nocturnal temperature changes at the individual stations below the mean ridge height to the low-cloud ratio at the nearest satellite pixel (Fig. 8). Stronger cooling $\left(<-1 \mathrm{~K} \mathrm{~h}^{-1}\right)$ preferentially occurred when the low-cloud ratio was below $40 \%$, which was most often the case during the first half of the night from 12 to 13 January (blue markers in Fig. 8) in agreement with the spatial distributions in Fig. 7. A temperature increase was most often detected during the second half of the night from 12 to 13 January (Fig. 7e and orange markers in Fig. 8), with no strong dependency on low-cloud ratio being visible. The large scatter in the regression analysis between near-surface temperature changes and low-cloud ratio suggests that other processes such as advection impact the near-surface temperature as well.

Besides the impact of the low-level clouds on the temperature distribution, there is also an interesting variability in near-surface temperature along the Columbia Valley. In the western part of the valley, where the valley floor is most narrow, the nearsurface temperature at the stations located at the lowest altitudes close to the Columbia River was often higher than those a few hundred meters up the slopes or in the eastern part of the valley at the end of the night (Figs. 5d-g). Usually, one would expect for the cold air on the slopes to drain into the valley and accumulate on the valley floor. As the low-cloud ratios at stations close to the river along the valley were fairly similar (not shown), this cannot explain the warmer temperatures in the western part. One reason for the higher temperatures in this narrow portion of the valley could be related to the vicinity of the Columbia River, which serves as a heat source as the surface temperature of the water body is higher than surface temperature of the snow-covered solid ground. The temperature in cold pools has been found to be sensitive to the land use and snow cover (e.g., Foster et al. 2017).

\section{2) STRATIFICATION IN THE LOWER PART OF THE COLD POOL WITH AND WITHOUT CLOUDS}

In this section, we assess the impact of clouds on the stratification in the lower part of the cold pool and investigate possible processes responsible for the observed warming during cloudy nights using the measurements at Wasco. Ceilometer backscatter profiles and cloud-base heights reveal that periods with fog (e.g., between approximately 0000 and 0600 PST 13 January and between 0500 and 0700 PST 14 January), periods with low-level clouds with bases between approximately 200 and $700 \mathrm{~m}$ AGL (around 650 and $1150 \mathrm{~m} \mathrm{MSL}$ ) and periods free of low-level clouds alternated (Fig. 9a). Low-level clouds existed during the daytime on 13 January and from the late morning of 14 January until around noon on 16 January. The latter period was briefly interrupted by a cloud-free period on the afternoon of 15 January. From the ceilometer measurements alone, we cannot obtain any information on the thickness or liquid water content of the clouds. Using LWP derived from TROPoe as a proxy reveals that liquid water content varied substantially, with LWP values ranging from around $150 \mathrm{~g} \mathrm{~m}^{-2}$ on 13 January, $50-100 \mathrm{~g} \mathrm{~m}^{-2}$ on 14 and 15 January to around $25 \mathrm{~g} \mathrm{~m}^{-2}$ on 16 January (Fig. 9b). On the afternoon of 15 January, LWP dropped to around $10 \mathrm{~g} \mathrm{~m}^{-2}$ and infrared brightness temperature gradually decreased. This indicates that the clouds became very thin, which was also evident in images taken with the sky camera in the visible range (not shown), leading to a rapid increase in net radiation and nearsurface temperature (Figs. 4b,h). This change in cloud characteristics was not at all visible in the backscatter profiles (Fig. 9a). This example nicely emphasizes the enhanced understanding of atmospheric conditions we can gain from instrument synergies. 

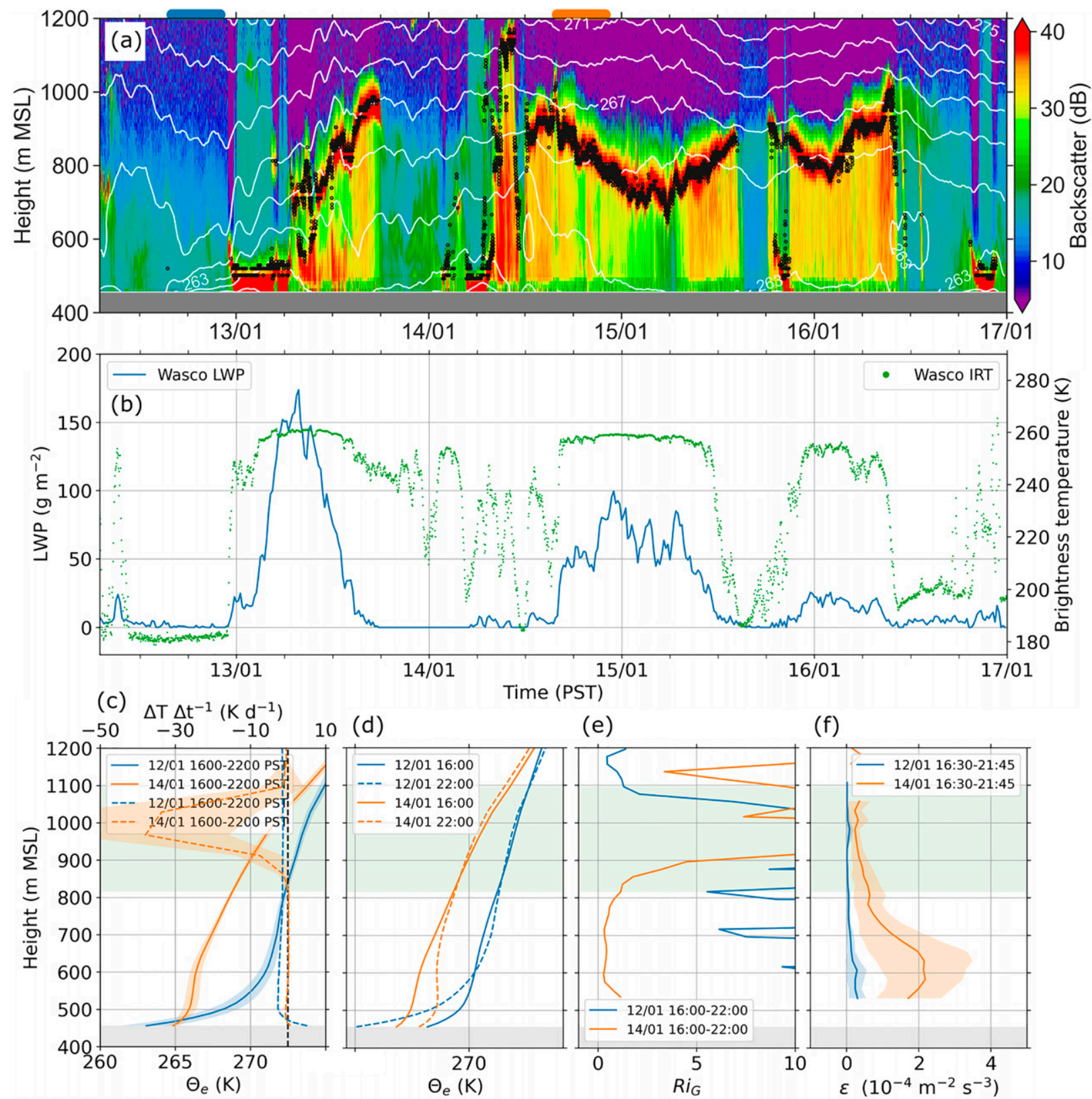

(e)

(f)

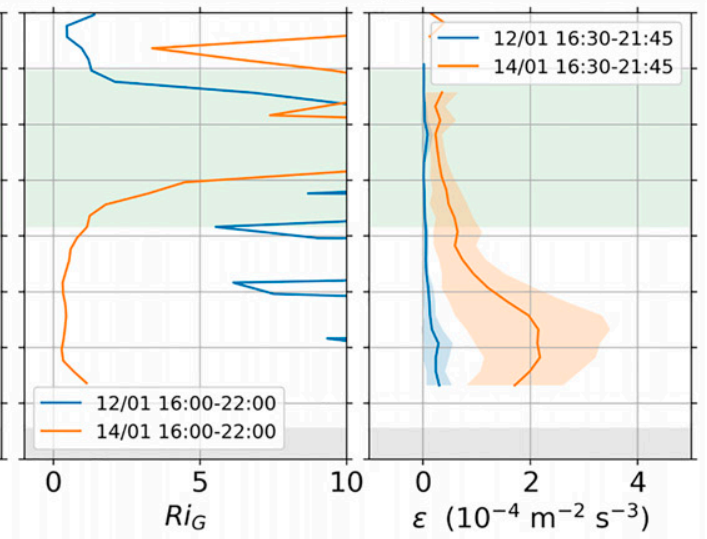

FIG. 9. Temporal evolution of (a) backscatter profiles measured by the ceilometer (color coded) and equivalent potential temperature profiles (contours) and (b) LWP (blue) and infrared brightness temperature IRT (green). (c) Mean equivalent potential temperature (solid) and longwave heating rate (dashed) profiles, (d) equivalent potential temperature profiles, (e) mean gradient Richardson number profiles, and (f) mean turbulence dissipation rate $\varepsilon$ profiles measured by the RWP. Temperature profiles and LWP are retrieved with TROPoe, and $\mathrm{Ri}_{g}$ is calculated from TROPoe temperature profiles and RWP high-resolution wind profiles. In (c) and (f), colored shading indicates the standard deviation, and the green shaded area indicates the mean cloud layer between 1600 and 2200 PST 14 Jan. All measurements are taken at Wasco.

In the absence of clouds, a strong surface inversion of around $100 \mathrm{~m}$ depth formed during nighttime, for example, between 1600 and 2200 PST 12 January (Figs. 9a,c,d). The surface inversion during the corresponding period on a night with lowlevel clouds (14 January) was shallower and much weaker and the moist static stability in the lower few hundred meters was reduced. Using a rapid radiative transfer model, we calculated the mean longwave radiative heating rates for both nights. During cloud-free conditions radiative cooling of around $2 \mathrm{~K} \mathrm{day}^{-1}$ was present above approximately $30 \mathrm{~m}$ AGL (Fig. 9c). The estimated longwave heating rates indicated weaker radiative cooling close to the surface than above, which 
(a) 04-10 PST 17 Jan

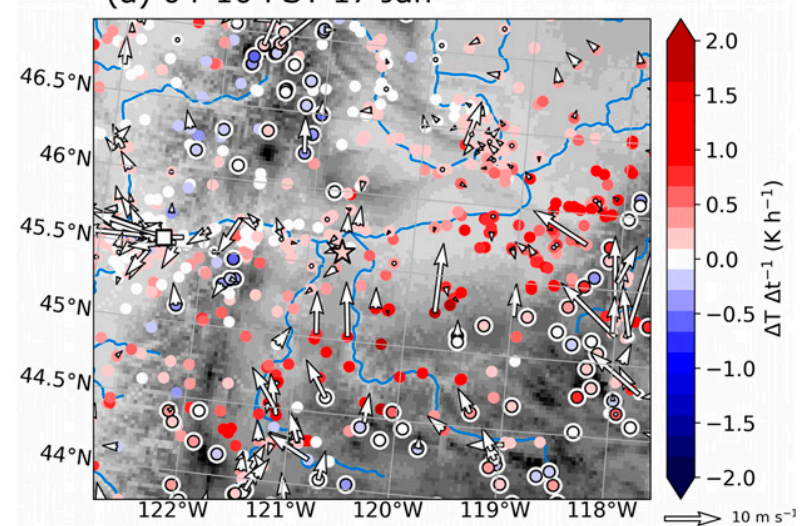

(b) 22 PST 17 Jan - 10 PST 18 Jan

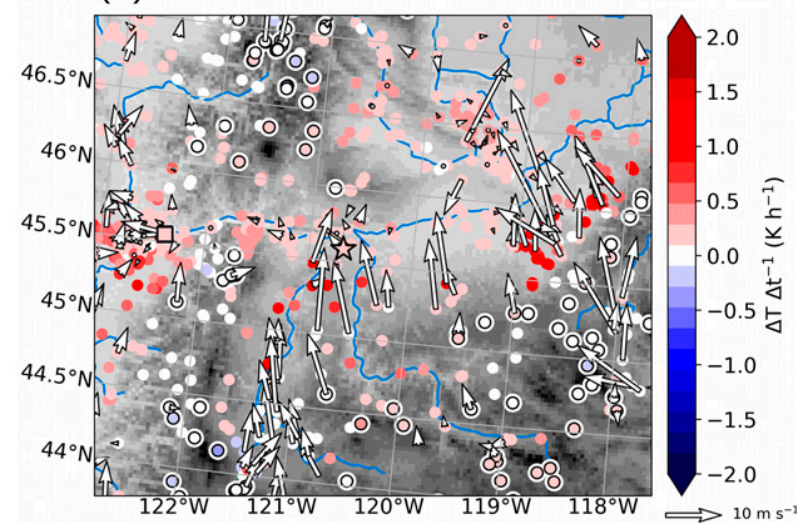

FIG. 10. Spatial distribution of near-surface temperature change (color coded) and horizontal wind vector (arrows) from the surface stations for different time periods. The wind vector at the end of the period is plotted. The locations of Troutdale and Wasco are indicated by the square and star, respectively. Whiteblack outlines mark stations located above the mean ridge height. Gray shading shows terrain height, and rivers are indicated in blue.

might seem somewhat surprising. This could be explained by the large sensitivity of near-surface radiative cooling under stable conditions to the surface-air temperature contrast (e.g., Hoch et al. 2011), which in our case depended on the assumed emissivity of the snow-covered surface. In the presence of low-level clouds on 14 January, longwave radiative cooling rate changes were negligible below the clouds and strong radiative cooling occurred near the cloud top (Fig. 9c). This is consistent with the longwave radiative heating profiles reported by Turner et al. (2018) for Arctic clouds.

The absence of substantial longwave radiative heating in the subcloud layer on 14 January (Fig. 9c) implies that another process had to be responsible for the observed increase of temperature of up to $1.5 \mathrm{~K}$ below the cloud base between 1600 and 2200 PST (Fig. 9d). At the end of the $6 \mathrm{~h}$ period, the stratification in the middle of the subcloud layer was near moist adiabatic and equivalent potential temperature values were similar to the ones near cloud base, which suggests that warmer air had been mixed downward. To investigate if turbulent mixing was possible, we calculated the gradient Richardson number $\mathrm{Ri}_{g}$. If $\mathrm{Ri}_{g}$ is positive but below a critical threshold, turbulence can be produced mechanically despite a stable stratification (e.g., Stull 1988). The threshold values reported in the literature are typically below 1 but vary depending on the depth of the layer over which the gradient is calculated. The small values of $\mathrm{Ri}_{g}(<0.4)$ in the subcloud layer (Fig. 9e) indicate that turbulent mixing was indeed possible, which was confirmed by a higher turbulence dissipation rate (measured by the RWP) relative to cloud-free conditions (Fig. 9f). The low $\mathrm{Ri}_{g}$ values were caused by vertical wind shear in a weakly stratified environment as the easterly flow accelerated with height (Figs. 3d and 9d). Top-down mixing induced by the longwave radiative cooling near cloud top (Fig. 9c) likely contributed to the weak moist static stability in the subcloud layer. This process was also suggested by, for example, Holmes et al. (2015) and Sun and Holmes (2019) who observed near moist-adiabatic subcloud layers and enhanced vertical mixing and surface turbulence relative to cloud-free cold-pool periods. VanReken et al. (2017) found lower pollutant concentrations in a cold pool in the Yakima Valley in the presence of low-level clouds relative to cloud-free periods and related this to decreased stability and stronger mixing. For the remainder of the night of 14/15 January, the stratification did not change much, and turbulence dissipation rates remained high. Many of the surface stations in the central part of the cloud-filled Columbia Valley observed warming during this night, which suggests that the process responsible for the warming at Wasco, that is, turbulent mixing, was present in other parts of the valley as well.

\section{c. Decay of the cold pool}

On the second half of the night of 16 to 17 January, the inversion at Wasco started to subside associated with a strong temperature increase in the layers below and around the mean ridge height (Figs. $3 b$ and $4 b$ ). Simultaneously, many of the surface stations in the southern part of the CRB showed a warming of several degrees (Fig. 10a). To better illustrate the temporal evolution and height dependence of the temperature changes observed at the surface stations, 6-hourly pseudovertical profiles of temperature between 1600 PST 16 January and 1600 PST 19 January are shown in Fig. 11. Although the temperature warmed in all layers below the mean ridge height during this three-day period, the timing of the warming clearly depended on height, as discussed below. The interface between the cold air below and warm air aloft descended with time and gradually affected the surface stations at lower altitudes. Two periods with particularly strong temperature changes stick out: (i) between 0400 and 1000 PST 17 January, a particular strong increase of more than $8^{\circ} \mathrm{C}$ occurred in the layer between 800 and $1000 \mathrm{~m}$ MSL, while it only warmed by $2^{\circ}-4^{\circ} \mathrm{C}$ below $800 \mathrm{~m}$ MSL. (ii) Between 2200 PST 17 January and 1000 PST 18 January, the layer between around 300 and $800 \mathrm{~m}$ MSL warmed by more than $5^{\circ} \mathrm{C}$ on average during the $12 \mathrm{~h}$ period, which lowered the bottom of the inversion to around $300 \mathrm{~m}$ MSL. The spatial distribution of the heating rates during the respective time period reveals that the mean warming during the first period was largely caused by 


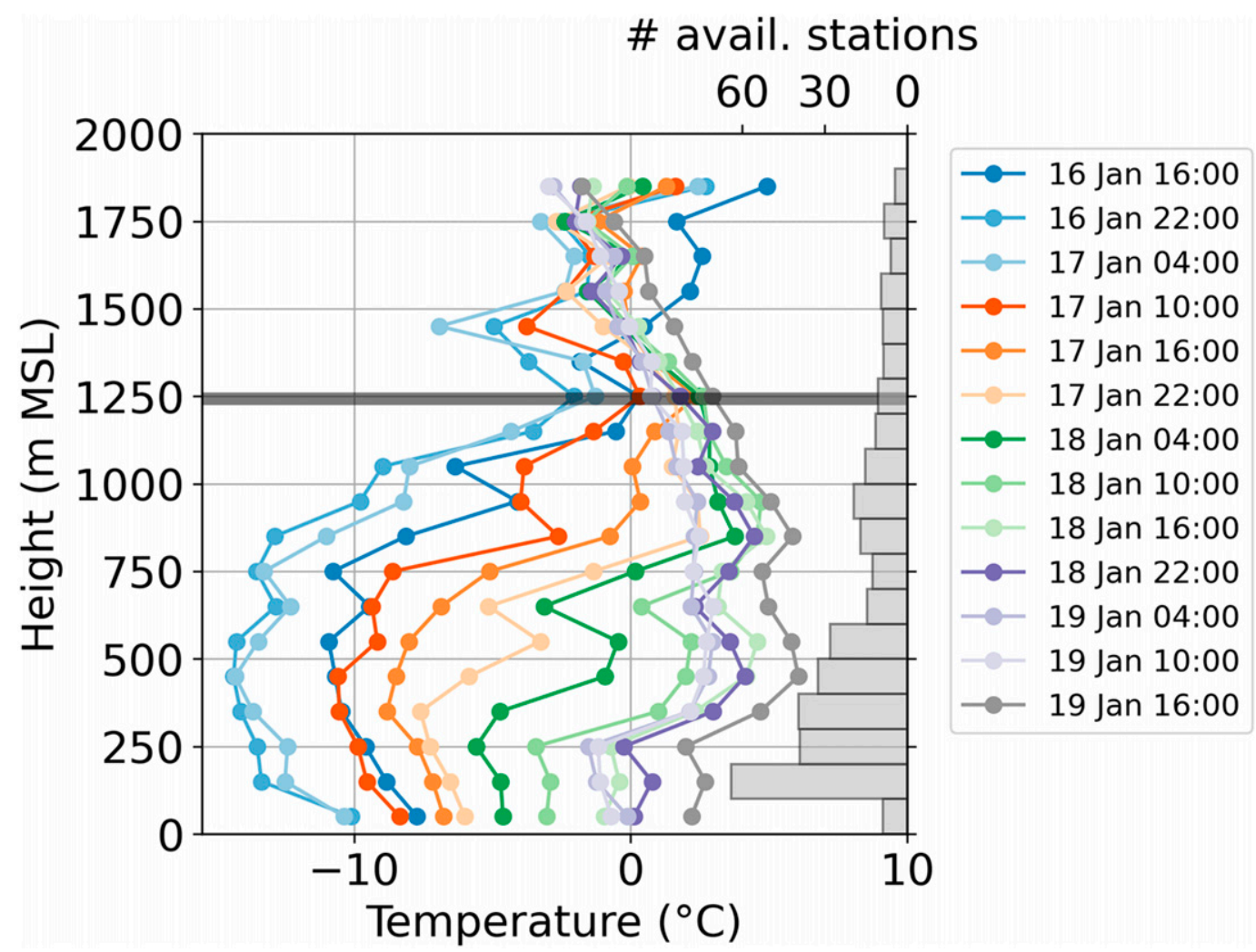

FIG. 11. Six-hourly pseudovertical temperature profiles from the surface stations east of the Cascade Range (area indicated in Fig. 1) between 1600 PST 16 Jan and 1600 PST 19 Jan. The lines show the mean temperature values calculated for 100-m height bins. Gray horizontal bars give the number of stations in the respective height bin. The horizontal line marks the mean ridge height.

stations on the upper Blue Mountain slopes in the south of the Columbia Valley and on the floor of the Deschutes Valley (Fig. 10a). The warming during the second period could mainly be attributed to the stations on the lower Blue Mountain slopes (Fig. 10b). Although near-surface warming occurred throughout the CRB during phase 3 (Fig. 10), it was strongest in the southern part of the $\mathrm{CRB}$ allowing cooler temperatures to persist in and north of the Columbia Valley (Fig. 5h,i). Strong southerly wind prevailed at the slope stations and in the Deschutes Valley (e.g., evident at 1000 PST 18 January in Fig. 5i) and only decayed after midnight on 19 January, which agrees with the decrease in wind speed seen in the profile at Wasco. In the lowest portion of the Columbia Valley and the Pasco subbasin, that is, below around $300 \mathrm{~m}$ MSL, a cold pool remained with temperatures being several degrees colder than aloft (Figs. 5i and 11). Daytime heating eventually increased the temperature also in the lower part of the Columbia Valley and together with the cooling above around $1500 \mathrm{~m}$ MSL (Figs. 3b, 4b, and 11), which had started on 18 January, the cold pool in the area was largely eroded by the afternoon of 19 January and only a weakly stably stratified layer persisted below ridge height. The near-surface temperature difference between west and east of the CRG was largely removed by 19 January and weak to moderate southwesterly wind prevailed throughout the area (Figs. 3 and 4a-f). The easterly gap flow was very shallow and was only observed at the surface stations in the lowest part of the CRG at and directly west of Troutdale (Fig. 4e).

\section{Discussion}

During the evolution, maintenance, and decay of the cold pool, we saw observational evidence for different processes that have also been reported in other cold-pool studies. The cold air in lower layers initially formed due to synoptically driven horizontal cold-air advection. The strong temperature inversion then developed about $24 \mathrm{~h}$ later as a result of warming above the mean ridge and was enhanced by cooling in low layers. Warming aloft is a common process in cold-pool evolution and maintenance, but the reasons for the warming may differ from case to case. During one of the cold-pool events in the Pasco subbasin studied by Whiteman et al. (2001) horizontal warm air advection with a strong southwesterly wind was responsible for the warming, while during another event descending motion on the lee slopes of the Cascade Range primarily resulted in the temperature increase (Whiteman et al. 2001; Zhong et al. 2001). Cold pools in the Salt Lake Valley in Utah are often associated with synoptic-scale subsidence that leads to warming, drying, and the generation of a very stable elevated layer (Lareau et al. 2013; Wei et al. 2013; Lu and Zhong 2014). A low moisture content in the stable layer may help to 
(a) Troutdale

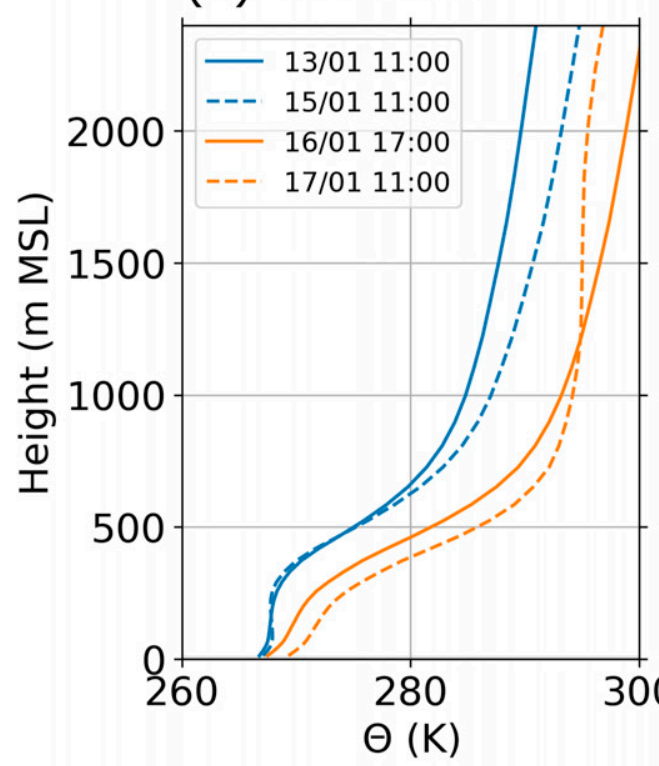

(d) Wasco

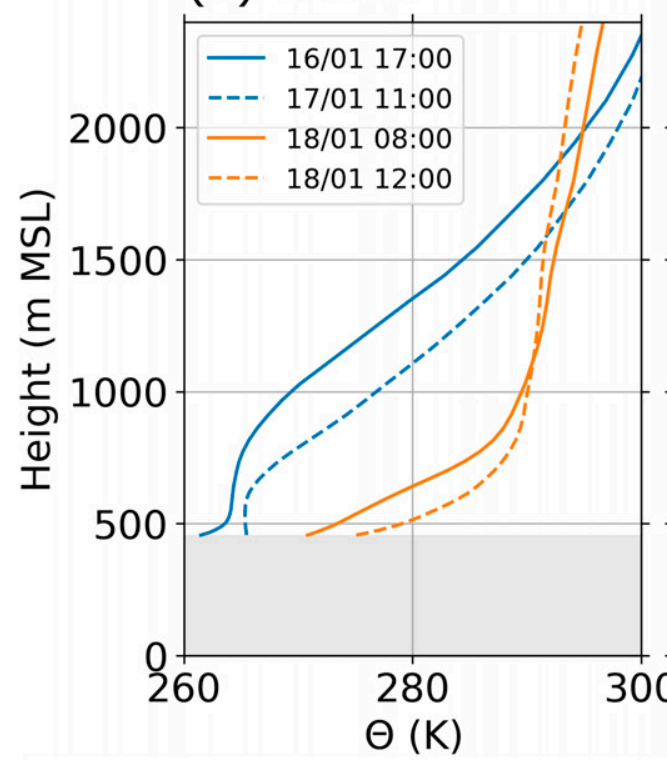

(b)

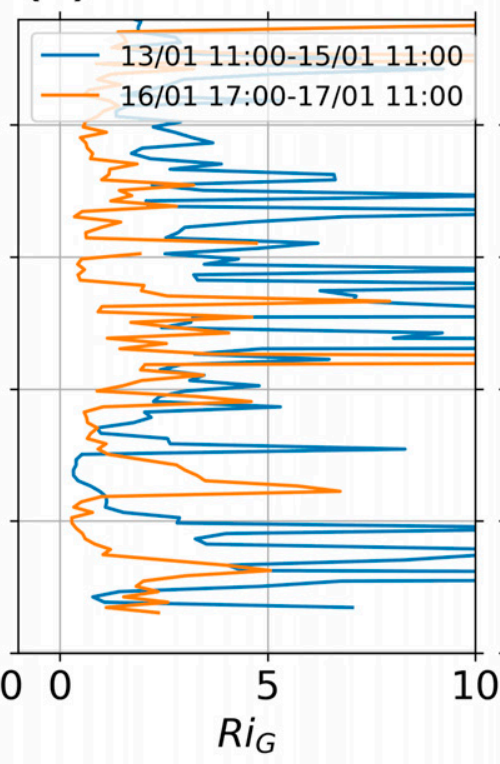

(e)

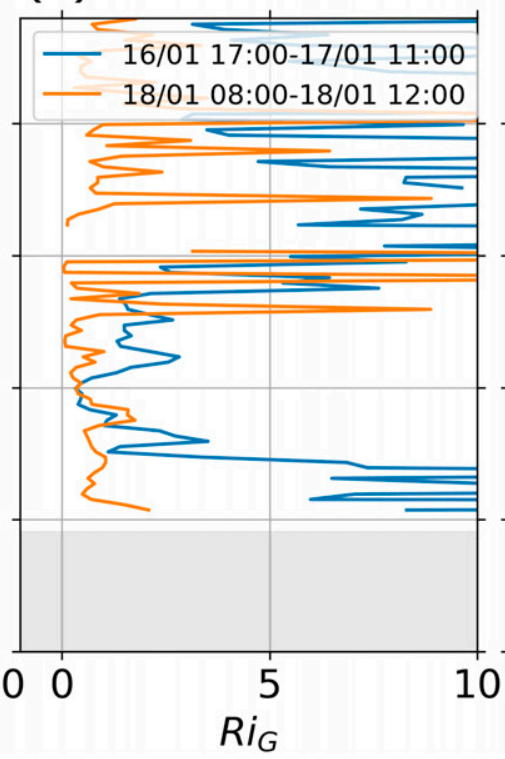

(c)

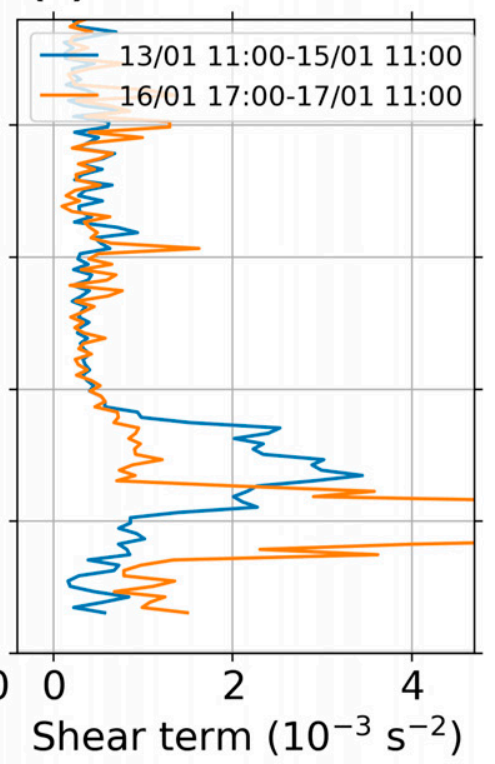

(f)

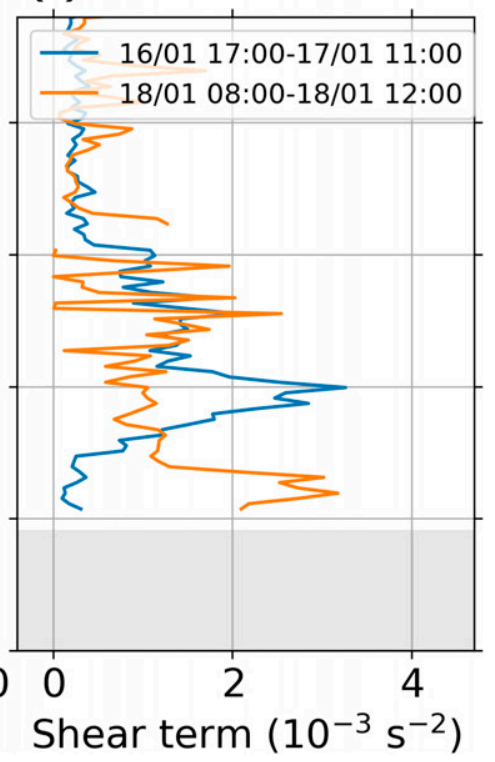

FIG. 12. Profiles of (a),(d) potential temperature $\boldsymbol{\Theta}$ at different times, (b),(e) mean gradient Richardson number, and (c),(f) mean horizontal wind shear $\left(\Delta u \Delta z^{-1}\right)^{2}+\left(\Delta v \Delta z^{-1}\right)^{2}$ calculated for the periods given in the legend at (top) Troutdale and (bottom) Wasco. Temperature profiles are retrieved with TROPoe, and wind profiles are from high-resolution wind profiler measurements.

distinguish warming due to subsidence from warming due to horizontal advection. The warming we observed in our study was probably affected by several of these processes. The warming at the beginning of phase 2 , which initiated the formation of the strong temperature inversion and was visible in profiles at Troutdale and Wasco (Figs. 3a,b and 4a,b) as well as in the pseudovertical temperature profiles east of the Cascade (Fig. 6), was likely due to synoptic-scale subsidence, as the large-scale wind in the layer with warming was weak and the warming was accompanied by a decrease in water vapor content (not shown).
The change in wind direction that accompanied the warming on 15 January indicates that warm air was horizontally advected by the large-scale flow (Fig. 2c) and was responsible for the strengthening of the inversion. As the warming during phase 2 was observed at Wasco as well as at Troutdale, that is, west and east of the Cascade Range, descending motion on the lee slopes of the Cascade Range due to downslope winds probably played a minor role if at all for the evolution and maintenance of the cold pool. The warming aloft on 16 January, which initiated the coldpool decay, is associated with an increase in moisture and wind 
speed and a shift to southerly wind direction. Simultaneously the inversion descended. The descent was stronger at Wasco than at Troutdale and strongly resembles the cold-pool case studied by Whiteman et al. (2001) and Zhong et al. (2001) and suggests that mountain waves and downslope winds on the slopes of the Blue Mountains south of the Columbia Valley played an important role. Supported by the observation that the northern part of the CRB remained colder near the surface than the southern part, it is also possible that the cold pool was displaced by the strong southerly wind and the cold-pool top was tilted similar to what Lareau and Horel (2015) found in the Salt Lake Valley in Utah and Haid et al. (2020) observed in the Inn Valley in Austria. The near-surface temperature distribution also bears some similarity to the first cold-pool case shown by Whiteman et al. (2001), where warm air progressively displaces the cold air in the cold pool, while some remnants of cold air remained trapped in the lowest-lying parts of the valley.

The simultaneous occurrence of strong southwesterly wind and the descending inversion suggests that turbulent erosion may have played a role in the inversion descent and the final decay of the cold pool. Besides horizontal warm air advection, turbulent erosion may lead to the descent of the cold-pool top as turbulence generated by wind shear gradually downward mixes warmer air (Whiteman et al. 2001). To investigate if this mechanism is likely, $\mathrm{Ri}_{g}$ can be used (e.g., Lareau and Horel 2015; Haid et al. 2020). We calculated profiles of $\mathrm{Ri}_{g}$ at Wasco for two periods when the temperature inversion descended (Figs. 3b, 12d-f). From 16 to 17 January, that is, before the warm front passed the area, the inversion descended by several hundred meters resulting in a decrease of the depth of the weakly stratified layer adjacent to the surface (Fig. 12d). On 18 January, after the warm front had passed, the inversion touched the ground and warming in lower layers decreased the inversion strength over time. During both periods strong horizontal wind shear (Fig. 12f) and associated low $\mathrm{Ri}_{g}(<1)$ (Fig. 12e) were observed in the stably stratified layers indicating that turbulent downward mixing of warm air likely played a role in the inversion descent.

When the inversion in the CRB started to descend on 16 January, the gap-flow depth at Troutdale also started to decrease along with the temperature inversion capping it and the air in the lower $1000 \mathrm{~m}$ warmed (Figs. 3a,c and orange curves in $12 \mathrm{a}$ ). Similar to Wasco, strong wind shear and low $\mathrm{Ri}_{g}$ existed in the lower part of the inversion (Figs. 12a-c). It is interesting to see that also during the persistent phase of the cold pool (phase 2), strong horizontal wind shear and low $\mathrm{Ri}_{g}$ were found at the top of the gap flow in the strongly stably stratified layer (blue curves in Figs. 12a-c). However, the inversion did not descend and the temperature in the gap flow did not increase. It is likely that a balance between turbulent downward mixing of warm air and horizontal cold-air advection from the CRB caused the stationary conditions in the gap flow during phase 2. Once the cold pool in the CRB started to weaken, turbulent mixing possibly became dominant and together with the stronger synoptic-scale impact led to the observed warming and shallower gap flow.

In section $4 \mathrm{~b}$, we investigated the impact of fog and clouds on the cold-pool characteristics and found that the clouds reduced the radiative cooling in the lower layers, allowed turbulent downward mixing of warm air by reducing the static stability, and thus prevented the near-surface temperature from further cooling and the cold pool from getting stronger over the multiday period. The temperature in the lower part of the cold pool at the beginning of the decay is decisive for the amount of energy needed to break up the cold pool and thus for the time of its decay. Failure to correctly represent the lowlevel clouds in a numerical model may thus lead to a wrong decay time, even if all other processes responsible for the decay were captured by the model. In the numerical simulations by Zhong et al. (2001) the cold pool in the Pasco subbasin was destroyed nearly at the same time (by a combination of cold-air advection aloft and the evolution of a convective boundary layer) whether low-level clouds were previously present or not. However, this finding may depend on the processes responsible for the decay. Besides their impact on the longwave radiation, the clouds also impact the shortwave radiation budget by reducing the amount of energy reaching the surface. In our case, this impact is likely less relevant as wintertime insolation is in general small (Zhong et al. 2001) and is further reduced by the high albedo of the snow-covered surface (e.g., Vrhovec and Hrabar 1996; Grachev et al. 2020). Even without the clouds it is most unlikely that daytime heating would lead to the breakup of the strong and deep elevated temperature inversion between around 1200 and $2000 \mathrm{~m}$ MSL.

The temperature profiles retrieved with TROPoe at Wasco and Troutdale provided new insights into the vertical structure of the cold pool in the CRB and the gap flow at the gap-exit region of the CRG. A large part of the information in the retrieved profiles comes from the passive MWRs and previous studies showed that they often failed to correctly represent elevated temperature inversions (e.g., Crewell and Löhnert 2007). In our analysis, the inclusion of the RASS data helped to overcome this problem. The good agreement of the strength and depth of the temperature inversion between Wasco and the pseudovertical profiles and the fact that the bottom of the inversion was associated with a turn from easterly wind to varying direction above gave us confidence that our combined MWR + RASS retrievals performed well and that the temperature structure was well captured. Also, the differences in low-level stability detected during cloudy and cloud-free coldpool periods are physically consistent, which increases credibility. While we see large potential of TROPoe for the study of thermodynamic profiles in complex terrain, the performance of the retrieval in different atmospheric conditions, cold pools, and valley geometries remains to be investigated.

\section{Summary and conclusions}

We used comprehensive remote sensing and in situ measurements collected during the WFIP2 campaign to investigate a persistent cold pool in the CRB associated with a strong gap flow through the CRG on 10 to 19 January 2017. By combining profile remote sensing measurements at Troutdale, at the gapexit region of the CRG, and Wasco, in the Columbia Valley, with surface measurements from several hundred surface stations and satellite images we were able to study the vertical and 
horizontal structure of the cold pool during its formation, maintenance, and decay and to identify which processes were involved. For the first time, an optimal estimation physical retrieval including both RASS and MWR data was used to study the vertical thermodynamic structure of the persistent cold pool and gap flow. By combining information from multiple instruments, the retrieval allowed us to overcome limitations of the individual instruments, for example, limited vertical range of the RASS and limited vertical resolution of the MWR, and to get the best possible information on the vertical structure.

The evolution of the persistent cold pool and the gap flow was governed by a combination of multiscale processes. Prior to the evolution of the actual cold pool in the CRB, synoptically driven easterly flow brought cooler air in the area and led to a very strong gap flow through the CRG. Subsequent warming above the mean ridge height at around $1200 \mathrm{~m} \mathrm{MSL}$ and cooling below led to the formation of a cold pool that persisted for roughly 4 days. The warming above probably resulted from large-scale subsidence and synoptically driven horizontal warm advection alike. The cold pool exhibited a layered structure: a shallow layer of a few hundred meters in depth adjacent to the surface revealed a diurnal cycle with the formation of a surface inversion during nighttime and a convective boundary layer during daytime. This diurnal cycle was modulated by the existence of low-level clouds. Above this layer, a layer with a near-isothermal stratification and easterly wind extended up to around the mean ridge height. This was topped by a very strong elevated temperature inversion up to around $2000 \mathrm{~m}$ MSL. This structure was evident in the profile measurements at Wasco but also in pseudovertical temperature profiles calculated from all surface stations in the CRB, which indicates a spatially extensive and horizontally homogeneous elevated inversion. The decay of the cold pool was initiated by synoptically driven warming with strong southwesterly flow and a gradual descent of the temperature inversion followed by cooling aloft. The descent of the inversion could have been related to turbulent shear-induced mixing and downslope winds forming on the slopes of the Blue Mountains in the southern part of the CRB.

A gap flow through the CRG existed for most of the 10-day period and its strength was well correlated with the cross-Cascade pressure difference. While the pressure difference prior to the cold-pool evolution was related to the synoptic-scale conditions, it was modified by the temperature difference between west and east of the Cascade Range during the persistent phase of the cold pool. The gap flow was topped by a strong temperature inversion and the gap-flow depth was rather constant around $600 \mathrm{~m}$. It only decreased when the cold pool in the CRB started to decay.

The multiscale processes at play during the cold pool, especially the effect of the low-level clouds and their subtle impact on the thermodynamic structure of the cold pool, impose a challenge for numerical weather prediction models. The correct representation of a cold pool-in particular of the decay when weak wind in lower layers can rapidly accelerate-is, however, relevant for wind energy forecasts. The results from this study will form the basis of a future model study with the new version of NOAA's High-Resolution Rapid Refresh model (HRRRv4) in which the model's capability in capturing the cold-pool and gap-flow characteristics and processes will be evaluated. Depending on the model performance, open points that could not be addressed with the observations are planned to be investigated with the model. For example, from the observations there is evidence that downslope winds, turbulent mixing, horizontal displacement, and a tilt of the cold-pool top might have played a role during the cold-pool decay. The relative importance of these processes remains, however, unclear, partly because information on the three-dimensional thermodynamic structure in the CRB is missing.

Acknowledgments. We thank all of the individuals for help with site selection, leases, instrument deployment and maintenance, data collection, and data quality control. Funding for this work was provided by the U.S. Department of Energy (DOE) Office of Energy Efficiency and Renewable Energy, Wind Energy Technologies Office, and by the NOAA Atmospheric Science for Renewable Energy program. This study was made possible in part because of the data made available by the governmental agencies, commercial firms, and educational institutions participating in MesoWest. The development of GSIP algorithms and associated products has been supported by the NOAA/NESDIS GOES Product Systems Development and Implementation (G-PSDI) program (Donald Gray, G-PSDI program manager, and Tom Schott, satellite product manager).

Data availability statement. All WFIP2 data are available on the DOE Data Archive and Portal (https://a2e.energy.gov/ data\#wfip2).

\section{REFERENCES}

Bianco, L., D. Gottas, and J. M. Wilczak, 2013: Implementation of a Gabor transform data quality-control algorithm for UHF wind profiling radars. J. Atmos. Oceanic Technol., 30, 26972703, https://doi.org/10.1175/JTECH-D-13-00089.1.

—, I. V. Djalalova, J. M. Wilczak, J. Cline, S. Calvert, E. Konopleva-Akish, C. Finley, and J. Freedman, 2016: A wind energy ramp tool and metric for measuring the skill of numerical weather prediction models. Wea. Forecasting, 31, 1137-1156, https://doi.org/10.1175/WAF-D-15-0144.1.

Bossavy, A., R. Girard, and G. Kariniotakis, 2013: Forecasting ramps of wind power production with numerical weather prediction ensembles. Wind Energy, 16, 51-63, https://doi.org/ $10.1002 /$ we.526.

Carter, D., K. Gage, W. Ecklund, W. Angevine, P. Johnston, A. Riddle, J. Wilson, and C. Williams, 1995: Developments in UHF lower tropospheric wind profiling at NOAA's Aeronomy Laboratory. Radio Sci., 30, 977-1001, https://doi.org/10.1029/ 95RS00649.

Chemel, C., G. Arduini, C. Staquet, Y. Largeron, D. Legain, D. Tzanos, and A. Paci, 2016: Valley heat deficit as a bulk measure of wintertime particulate air pollution in the Arve River Valley. Atmos. Environ., 128, 208-215, https://doi.org/ 10.1016/j.atmosenv.2015.12.058.

Crewell, S., and U. Löhnert, 2007: Accuracy of boundary layer temperature profiles retrieved with multifrequency multiangle microwave radiometry. IEEE Trans. Geosci. Remote Sens., 45, 2195-2201, https://doi.org/10.1109/TGRS.2006.888434. 
Flamant, C., and Coauthors, 2006: Föhn/cold-pool interactions in the Rhine Valley during MAP IOP 15. Quart. J. Roy. Meteor. Soc., 132, 3035-3058, https://doi.org/10.1256/qj.06.36.

Foster, C. S., E. T. Crosman, and J. D. Horel, 2017: Simulations of a cold-air pool in Utah's Salt Lake Valley: Sensitivity to land use and snow cover. Bound.-Layer Meteor., 164, 63-87, https:// doi.org/10.1007/s10546-017-0240-7.

Francis, N., 2008: Predicting sudden changes in wind power generation. North Amer. Windpower, 5, 58-60.

Grachev, A. A., C. W. Fairall, B. W. Blomquist, H. J. Fernando, L. S. Leo, S. F. Otárola-Bustos, J. M. Wilczak, and K. L. McCaffrey, 2020: On the surface energy balance closure at different temporal scales. Agric. For. Meteor., 281, 107823, https://doi.org/10.1016/j.agrformet.2019.107823.

Haid, M., A. Gohm, L. Umek, H. C. Ward, T. Muschinski, L. Lehner, and M. W. Rotach, 2020: Foehn-cold pool interactions in the Inn Valley during PIANO IOP2. Quart. J. Roy. Meteor. Soc., 146, 1232-1263, https://doi.org/10.1002/ qj.3735.

Hoch, S. W., C. D. Whiteman, and B. Mayer, 2011: A systematic study of longwave radiative heating and cooling within valleys and basins using a three-dimensional radiative transfer model. J. Appl. Meteor. Climatol., 50, 2473-2489, https://doi.org/ 10.1175/JAMC-D-11-083.1.

Holmes, H. A., J. K. Sriramasamudram, E. R. Pardyjak, and C. D. Whiteman, 2015: Turbulent fluxes and pollutant mixing during wintertime air pollution episodes in complex terrain. Environ. Sci. Technol., 49, 13 206-13 214, https:// doi.org/10.1021/acs.est.5b02616.

Horel, J., and Coauthors, 2002: MesoWest: Cooperative mesonets in the western United States. Bull. Amer. Meteor. Soc., 83, 211-226, https://doi.org/10.1175/15200477(2002)083<0211:MCMITW>2.3.CO;2.

Jordan, J. R., R. J. Lataitis, and D. A. Carter, 1997: Removing ground and intermittent clutter contamination from wind profiler signals using wavelet transforms. J. Atmos. Oceanic Technol., 14, 1280-1297, https://doi.org/10.1175/1520-0426(1997) 014<1280:RGAICC > 2.0.CO;2.

Lareau, N. P., and J. D. Horel, 2015: Dynamically induced displacements of a persistent cold-air pool. Bound.-Layer Meteor., 154, 291-316, https://doi.org/10.1007/s10546-0149968-5.

—, E. Crosman, C. D. Whiteman, J. D. Horel, S. W. Hoch, W. O. Brown, and T. W. Horst, 2013: The Persistent Cold-Air Pool Study. Bull. Amer. Meteor. Soc., 94, 51-63, https://doi.org/ 10.1175/BAMS-D-11-00255.1.

Lu, W., and S. Zhong, 2014: A numerical study of a persistent cold air pool episode in the Salt Lake Valley, Utah. J. Geophys. Res., 119, 1733-1752, https://doi.org/10.1002/2013JD020410.

Martucci, G., C. Milroy, and C. D. O'Dowd, 2010: Detection of cloud-base height using Jenoptik CHM15K and Vaisala CL31 ceilometers. J. Atmos. Oceanic Technol., 27, 305-318, https:// doi.org/10.1175/2009JTECHA1326.1.

McCaffrey, K., L. Bianco, and J. M. Wilczak, 2017: Improved observations of turbulence dissipation rates from wind profiling radars. Atmos. Meas. Tech., 10, 2595-2611, https://doi.org/ 10.5194/amt-10-2595-2017.

— , and Coauthors, 2019: Identification and characterization of persistent cold pool events from temperature and wind profilers in the Columbia River basin. J. Appl. Meteor. Climatol., 58, 2533-2551, https://doi.org/10.1175/JAMC-D-19-0046.1.

Mlawer, E. J., S. J. Taubman, P. D. Brown, M. J. Iacono, and S. A. Clough, 1997: Radiative transfer for inhomogeneous atmospheres: RRTM, a validated correlated- $k$ model for the longwave.J. Geophys. Res., 102, 16663-16 682, https://doi.org/ 10.1029/97JD00237.

Neiman, P. J., D. J. Gottas, and A. B. White, 2019: A two-coolseason wind profiler-based analysis of westward-directed gap flow through the Columbia River Gorge. Mon. Wea. Rev., 147, 4653-4680, https://doi.org/10.1175/MWR-D-190026.1 .

Pagès, M., N. Pepin, and J. Miró, 2017: Measurement and modelling of temperature cold pools in the Cerdanya Valley (Pyrenees), Spain. Meteor. Appl., 24, 290-302, https://doi.org/10.1002/ met.1630.

Reeves, H. D., and D. J. Stensrud, 2009: Synoptic-scale flow and valley cold pool evolution in the western United States. Wea. Forecasting, 24, 1625-1643, https://doi.org/10.1175/2009WAF2222234.1.

Sharp, J., and C. F. Mass, 2002: Columbia Gorge gap flow: Insights from observational analysis and ultra-high-resolution simulation. Bull. Amer. Meteor. Soc., 83, 1757-1762, https://doi.org/ 10.1175/1520-0477-83.12.1745.

— logical influence and synoptic evolution. Wea. Forecasting, 19, 970-992, https://doi.org/10.1175/826.1.

Shea, C., and B. Jamieson, 2011: Some fundamentals of handheld snow surface thermography. Cryosphere, 5, 55-66, https:// doi.org/10.5194/tc-5-55-2011.

Solheim, F., J. R. Godwin, E. Westwater, Y. Han, S. J. Keihm, K. Marsh, and R. Ware, 1998: Radiometric profiling of temperature, water vapor and cloud liquid water using various inversion methods. Radio Sci., 33, 393-404, https://doi.org/ 10.1029/97RS03656

Stull, R. B., 1988: An Introduction to Boundary Layer Meteorology. Kluwer Academic, 666 pp.

Sun, X., and H. A. Holmes, 2019: Surface turbulent fluxes during persistent cold-air pool events in the Salt Lake Valley, Utah. Part I: Observations. J. Appl. Meteor. Climatol., 58, 25532568, https://doi.org/10.1175/JAMC-D-19-0053.1.

Synoptic Data, 2021: Mesonet API. Accessed 6 April 2021, https:// developers.synopticdata.com/mesonet/.

Turner, D. D., and U. Löhnert, 2014: Information content and uncertainties in thermodynamic profiles and liquid cloud properties retrieved from the ground-based Atmospheric Emitted Radiance Interferometer (AERI). J. Appl. Meteor. Climatol., 53, 752-771, https://doi.org/10.1175/JAMC-D-130126.1.

— thermodynamic profile retrieval algorithm. IEEE J. Sel. Top. Appl. Earth Obs. Remote Sens., 12, 1339-1354, https://doi.org/ 10.1109/JSTARS.2018.2874968.

—, M. D. Shupe, and A. B. Zwink, 2018: Characteristic atmospheric radiative heating rate profiles in Arctic clouds as observed at Barrow, Alaska. J. Appl. Meteor. Climatol., 57, 953-968, https://doi.org/10.1175/JAMC-D-17-0252.1.

VanReken, T. M., and Coauthors, 2017: Role of persistent lowlevel clouds in mitigating air quality impacts of wintertime cold pool conditions. Atmos. Environ., 154, 236-246, https:// doi.org/10.1016/j.atmosenv.2017.01.043.

Vrhovec, T., and A. Hrabar, 1996: Numerical simulations of dissipation of dry temperature inversions in basins. Geofizika, 13, 81-96.

Wei, L., Z. Pu, and S. Wang, 2013: Numerical simulation of the life cycle of a persistent wintertime inversion over Salt Lake City. Bound.-Layer Meteor., 148, 399-418, https://doi.org/10.1007/ s10546-013-9821-2. 
Whiteman, C. D., and S. W. Hoch, 2014: Pseudovertical temperature profiles in a broad valley from lines of temperature sensors on sidewalls. J. Appl. Meteor. Climatol., 53, 2430-2437, https://doi.org/10.1175/JAMCD-14-0177.1.

_- X. Bian, and S. Zhong, 1999: Wintertime evolution of the temperature inversion in the Colorado Plateau basin. J. Appl. Meteor., 38, 1103-1117, https://doi.org/10.1175/ 1520-0450(1999)038<1103:WEOTTI >2.0.CO;2.

_ S. Zhong, W. J. Shaw, J. M. Hubbe, X. Bian, and J. Mittelstadt, 2001: Cold pools in the Columbia basin. Wea. Forecasting,
16, 432-447, https://doi.org/10.1175/1520-0434(2001)016<0432: CPITCB $>2.0 . \mathrm{CO} ; 2$.

Wilczak, J. M., and Coauthors, 2019: The Second Wind Forecast Improvement Project (WFIP2): Observational field campaign. Bull. Amer. Meteor. Soc., 100, 1701-1723, https://doi.org/ 10.1175/BAMS-D-18-0035.1.

Zhong, S., C. D. Whiteman, X. Bian, W. J. Shaw, and J. M. Hubbe, 2001: Meteorological processes affecting the evolution of a wintertime cold air pool in the Columbia basin. Mon. Wea. Rev., 129, 2600-2613, https://doi.org/10.1175/1520-0493(2001) 129<2600:MPATEO>2.0.CO;2. 